\title{
INHIBITION OF THIRST WHEN DEHYDRATED RATS DRINK WATER OR SALINE
}

by

\section{Myriam L. Hoffmann}

B.S. in Psychology, University of Pittsburgh, 1997

\author{
Submitted to the Graduate Faculty of \\ Arts and Sciences in partial fulfillment \\ of the requirements for the degree of \\ Master in Science
}

University of Pittsburgh 


\title{
UNIVERSITY OF PITTSBURGH \\ FACULTY OF ARTS AND SCIENCES
}

This thesis was presented

\author{
by \\ Myriam L. Hoffmann
}

It was defended on

April 11, 2006

and approved by

Edward M. Stricker, PhD, University Professor, Neuroscience

Alan F. Sved, PhD, Professor, Neuroscience

Linda M. Rinaman, PhD, Associate Professor, Neuroscience

Thesis Director: Edward M. Stricker, PhD, University Professor, Neuroscience 
Copyright (C) by Myriam L. Hoffmann 2006 


\title{
INHIBITION OF THIRST WHEN DEHYDRATED RATS DRINK WATER OR
}

\author{
SALINE \\ Myriam L. Hoffmann, M.S. \\ University of Pittsburgh, 2006
}

The present experiments sought to identify the physiological signals that inhibit thirst when dehydrated rats drink water or $\mathrm{NaCl}$ solution. Rats were deprived of drinking fluid but not food overnight. When allowed to drink again, the dehydrated animals consumed water or saline (0.05 M, 0.10 M, 0.15 M, or 0.20 M NaCl solution) almost continuously for 5-8 min before stopping. The volumes consumed were similar regardless of which fluid they ingested, but blood analyses indicated that increased plasma osmolality and decreased plasma volume, or both, still remained when drinking terminated. These results suggest that the composition of the ingested fluid is less significant than its volume in providing an early signal that inhibits thirst and fluid consumption by dehydrated rats. Analyses of the gastrointestinal tracts revealed that the cumulative volume in the stomach and small intestine correlated highly with the amount consumed regardless of which fluid was ingested. These and other results suggest that the volume of fluid ingested by dehydrated rats is sensed by stretch receptors detecting distension of the stomach and small intestine, which provide an early inhibitory stimulus of thirst. 
TABLE OF CONTENTS

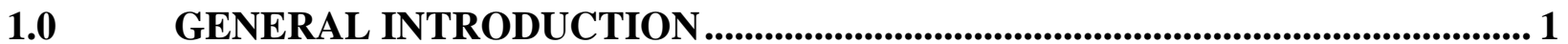

2.0 INHIBITION OF THIRST WHEN DEHYDRATED RATS DRINK WATER OR SALINE 8

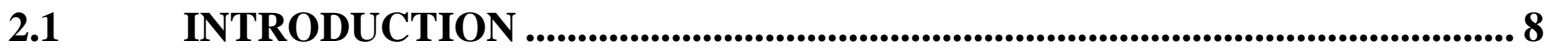



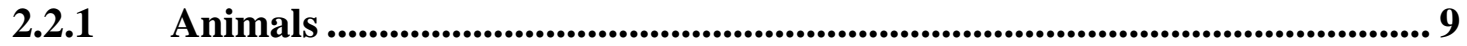

2.2.2 Experimental Protocols ........................................................................ 10

2.2.3 Effects of overnight water deprivation on fluid ingestion.......................... 10

2.2.4 Effects of urinary excretion on fluid ingestion in dehydrated rats ........ 11

2.2.5 Effects of initial fluid ingestion on gastrointestinal tract and plasma.... 11

2.2.6 Distribution of ingested fluid at various times after fluid ingestion....... 13

2.2.7 Calculations ............................................................................................................. 14

2.2.8 Statistical Analysis ......................................................................................... 15

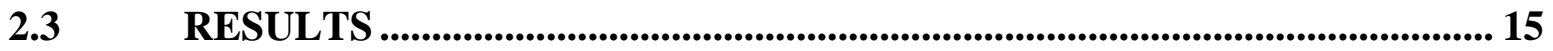

2.3.1 Effects of overnight water deprivation on fluid ingestion ......................... 15

2.3.2 Effects of urinary excretion on fluid ingestion in dehydrated rats ........ 16

2.3.3 Effects of initial fluid ingestion on gastrointestinal tract and plasma.... 16

2.3.4 Distribution of ingested fluid at various times after fluid ingestion....... 19

$2.4 \quad$ DISCUSSION .............................................................................................................. 19

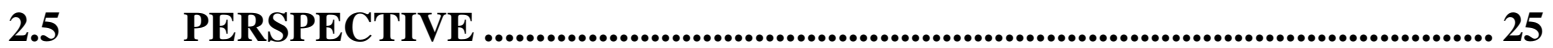

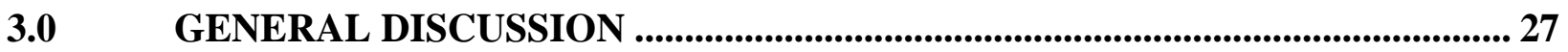

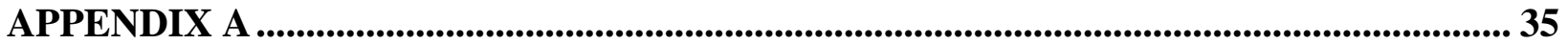

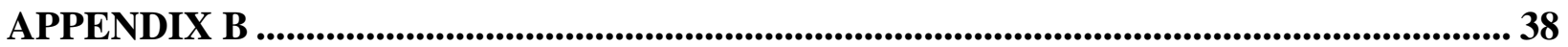

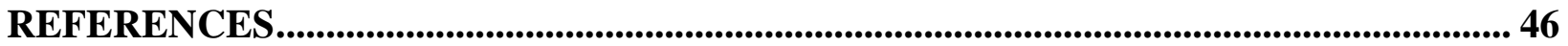




\section{LIST OF TABLES}

Table 1 Intake of water or $\mathrm{NaCl}$ solution by dehydrated rats during a 1-hr test session............. 35

Table 2 Plasma levels of $\mathrm{Na}+$ and protein in dehydrated rats given nothing, water or hypotonic saline, or isotonic or hypertonic saline to drink................................................................. 36 


\section{LIST OF FIGURES}

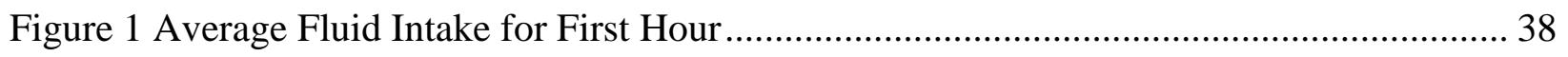



Figure 3A and 3B Gastric Fluid as a Function of Intake ................................................... 40



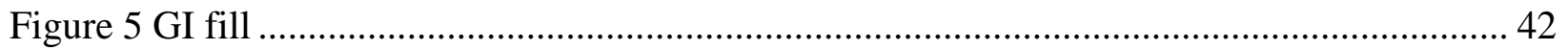

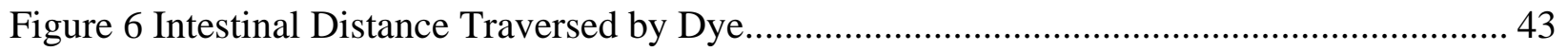

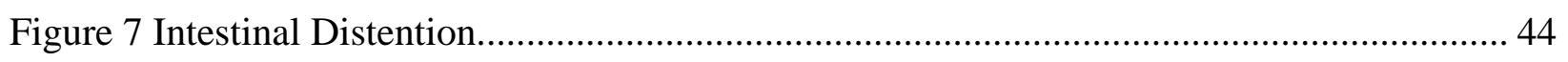

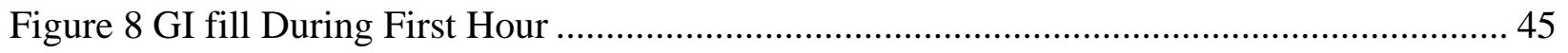




\subsection{GENERAL INTRODUCTION}

How does an animal know it is thirsty and that it needs to drink water? Where do the signals originate that tell an animal that its body fluid osmolality has risen? Is thirst the only mechanism by which an animal can defend its osmolality? Once the animal has begun to drink water, what is the nature and origin of the signals leading to the cessation of drinking? These questions continue to drive research in the general area of body fluid homeostasis, and much has already been learned.

The traditional view of the control of body fluid homeostasis and thirst in particular is that increases in the osmolality of systemic plasma are detected by cerebral osmosensitive cells located in the organum vasculosum of the lamina terminalis (OVLT) at the base of the third ventricle. These cells are special mainly in their connectivity. That is, they transduce changes in body fluid concentrations into a neural message that travels to additional nuclei in the hypothalamus, the most important of which to this Introduction are the supraoptic nucleus (SON), the paraventricular nucleus (PVN), and the median preoptic nucleus (MnPO) (Oldfield et al., 1994). The PVN and SON are responsible for the production and release of two hormones that are particularly important in the control of body fluid osmolality: vasopressin (VP) and, in rats, oxytocin (OT). When the magnocellular neurons in the PVN and SON are stimulated, they release VP (and/or OT) into the blood stream from their nerve terminals located in the posterior lobe of the pituitary gland. In the rat, the release of OT begins a cascade that ultimately causes a 
natriuresis (Verbalis et al., 1991), thereby decreasing plasma osmolality (pOsm) and blunting further increases. VP released into the general circulation acts on VP type $2\left(V_{2}\right)$ receptors in the kidney to increase the number of aquaporins in the distal tubule and collecting duct of the renal tubules (Nielsen et al., 1995). These aquaporins allow for water to be reabsorbed from tubular urine before it is excreted. The threshold for the stimulation of these physiological defenses is an increase above baseline concentration of only 1-2\% (Dunn et al., 1973; Stricker \& Verbalis, 1986). This very low threshold allows for the physiological responses to make an important contribution to the homeostatic regulation of body fluid osmolality. Because the system works so well, it is easy to take it for granted. For example, people with normal VP secretion excrete 2-3 liters of urine per 24-hr period. They are able to conduct their lives generally free from concern about access to fluids and restrooms. However, people who do not have normal VP secretion, for instance those with diabetes insipidus (DI), may excrete 25 liters of urine per day. This huge output must be balanced with huge intakes, and they are; patients with DI consume up to 25 liters of water per day, or $\sim 1$ liter per hour every hour of the day. Obviously, these needs require considerable time and attention, disturb sleep, and generally limit all other activities (Elkinton, 1961).

There is another familiar way in which animals respond to an increase in plasma osmolality, and that is to increase the amount of body fluid in which osmolytes are dissolved. This increase in body fluid volume is rapidly accomplished by consuming fluid. The OVLT is also involved in the stimulation of thirst, but the neural circuitry is not fully understood. What is clear is that the OVLT has projections to the MnPO, which projects to higher brain areas that ultimately mediate the sensation of thirst and water ingestion, because focal damage to these brain areas eliminates the drinking response to induced increases in pOsm (Mangiapane et al., 
1983; Thrasher et al., 1982). It should be noted that in experimental animals, thirst is traditionally defined operationally as the motivation to seek and consume water, which manifests itself in the animals working to obtain water and then ingesting it in measurable amounts. I will be using that definition of thirst in this report. The threshold for thirst in animals without competing stimuli is also a 1-2\% increase in pOsm (Fitzsimons, 1963).

Once sufficiently thirsty, the animal begins to drink water. Now the question that can be asked is, which signals tell the animal it has consumed enough water and should stop drinking before body fluids become overly dilute? The traditional view of this component in the control of fluid intake has been that the consumption of water leads to the dilution of body fluids and thereby removes the stimulus of thirst. However, a critical problem with this traditional view of a thightly regulated, long-loop negative-feedback system is that it does not take time into account. Animals generally drink for only a few minutes, yet for most animals the concentration of their systemic plasma has not even begun to decrease within that brief time frame (e.g., Thrasher et al., 1981). It takes additional time for substantial amounts of ingested water to empty from the stomach into the small intestine from which it can begin to affect body fluids.

For the past 20-25 years, research has begun to uncover the mechanism by which a presystemic signal inhibits thirst and VP secretion independent from and earlier than the signals arising from the cerebral osmoreceptors. Ramsay, Thrasher, and colleagues conducted a series of seminal studies that addressed the early inhibition of VP secretion and thirst in awake, behaving dogs. They found that when dogs were made thirsty by overnight water deprivation and then were allowed access to water, they drank for an average of only a few minutes yet it took $~ 30$ minutes for their systemic pOsm to return to baseline levels. The time course of decay of plasma VP (pVP) was consistent with a very rapid and complete inhibition of VP secretion, which 
occurred despite the persistence of an elevated pOsm in systemic blood (Thrasher et al., 1981). The authors concluded that the early inhibition of thirst and VP secretion arose from an oropharyngeal signal associated with the pattern of rapid swallowing that occurs during drinking, essentially a volume-metering system. They arrived at this conclusion because they found the same inhibition of thirst and VP secretion when dehydrated dogs drank isotonic saline solution, or even hypertonic saline, instead of water (Thrasher et al., 1981; Appelgren et al., 1991). The inhibitory signal derived from the act of drinking these solutions lasted for $\sim 20$ minutes, by which time the ingested fluid had equilibrated with body fluids and pVP had returned to a level appropriate to the current pOsm. (That is, there was no resumption of VP secretion when water was drunk, whereas pVP returned to the same preingestion level when isotonic saline was consumed because pOsm had not changed, and pVP was higher when hypertonic saline had been consumed because pOsm had increased.) The inhibition itself was identical across concentrations of ingested fluid (Thrasher et al., 1981; Appelgren et al., 1991). Even more direct evidence for the oropharyngeal signal inhibiting thirst and VP secretion in dogs came in additional findings that thirst and VP secretion still were inhibited when dogs drank water and all the ingested fluid drained from the stomach through open gastric fistulae, which eliminated the ability of ingested fluid to affect pOsm (Thrasher et al., 1981). Thrasher and collegues (1981) also infused fluids directly into the stomach via these fistulae and found that there was no effect on VP secretion until the infused fluids had influenced systemic pOsm (Thrasher et al., 1981). A simultaneous, presystemic, and persistent oropharyngeal inhibition of thirst and VP secretion has also been identified in both human and non-human primates (Arnauld \& DuPont, 1982; Geelen et al., 1984) and in sheep (Blair-West et al., 1985). These findings led to the widespread belief that 
oropharyngeal signals were the mechanism used by all mammals to provide presystemic inhibition.

Because the most widely used experimental animal is the rat, in 2000 Huang and colleagues attempted to extend these finding to rats and to a different model of thirst and VP secretion. Specifically, an infusion of $2 \mathrm{M} \mathrm{NaCl}$ at $2 \mathrm{ml} / \mathrm{hr}$ for $\sim 3.5 \mathrm{hr}$ raised pOsm from $\sim 305$ to $\sim 320 \mathrm{mOsm} / \mathrm{kg}$, and pVP from baseline values of $\sim 5 \mathrm{pg} / \mathrm{ml}$ to $\sim 40 \mathrm{pg} / \mathrm{ml}$. Rats were then given access to water or isotonic saline to drink for 5 min. Blood was assayed for pVP and pOsm. Rats showed a rapid drop in pVP values consistent with an early inhibition of VP secretion beginning a minute or two after the initiation of drinking water (assuming that the half-life of circulating VP is $\sim 5$ minutes) (Huang et al, 2000). This inhibition occurred despite the fact that systemic pOsm had not been affected by the ingested water because the infusion continued during the drinking portion of the test and thereby buffered the diluting effect of ingested water. These data demonstrate that the inhibition of VP secretion associated with water ingestion did not arise from cerebral osmoreceptors. Surprisingly, there was no inhibition of VP secretion when animals drank isotonic saline instead of water. This striking result led to the idea that rats utilized a different signal than dogs for the presystemic inhibition of VP secretion (Huang et al., 2000). However, the difference between these findings and those from all other mammalian species tested could also have occurred because the model of thirst used was different, or because the level of VP secretion was considerably more elevated in association with a much higher osmotic stimulus. Additionally, it seemed relevant that there is a small but significant plasma volume deficient when animals are deprived of water overnight. This depletion is $\sim 10$ $15 \%$, and it is sufficient to stimulate thirst and VP secretion independent from osmotic stimuli (Stricker \& Verbalis, 1986). Note that there is no volumetric component of thirst in the animals 
infused with hypertonic saline, so they do not have a compound stimulus for thirst and VP secretion.

To address these multiple differences in experimental design, we redid the studies but used overnight water deprivation to stimulate thirst, the same model that Thrasher and colleagues (1981) had used but with rats as experimental subjects. Dehydrated rats were given either water or isotonic saline to drink, and some animals were also fitted with gastric fistulae to prevent postgastric effects of the consumed fluid. Subgroups of rats were sacrificed at the end of their first drinking bout, while others were interrupted in their drinking to ascertain the time course of the fate of ingested water. All animals had their blood assayed for pVP and pNa. The data from these experiments were consistent with the findings of Huang et al. (2000). That is, dehydrated rats showed an inhibition of VP secretion soon after they began to drink water, whereas no inhibition of VP secretion was seen when rats drank isotonic saline or when they drank water but it drained through an open gastric fistula (Stricker \& Hoffmann, 2005).

These findings constitute strong evidence that the presystemic mechanism utilized by the rat to inhibit VP secretion is different from that used by the dog for the same general purpose, and they are consistent with the hypothesis that visceral osmoreceptors play an important role in the process. Not only is this inhibition in rats linked to the osmotic properties of the ingested fluid, but the inhibition of VP secretion is uncoupled from the inhibition of thirst. Drinking continues for several minutes after VP secretion has ceased. In fact, at the time the dehydrated rat takes its first significant pause from drinking water, its pNa had essentially returned to baseline values. The volumetric deficit, however, persists because the volume depletion is not repaired by the water intake. Yet fluid intakes were comparable when dehydrated rats drank isotonic saline instead of water (Stricker \& Hoffmann, 2005). The mechanisms that inhibit thirst clearly 
do not derive from the concentration of the ingested fluid, which leaves open the possibility that they derive from the volume of fluid consumed. This thesis was designed to address that possibility. 


\subsection{INHIBITION OF THIRST WHEN DEHYDRATED RATS DRINK WATER OR SALINE}

\section{$2.1 \quad$ INTRODUCTION}

Water deprivation elicits thirst and secretion of neurohypophyseal vasopressin (VP), the antidiuretic hormone, in rats and other animals (Stricker \& Verbalis, 2002). When dehydrated animals drink water, both responses are inhibited before systemic rehydration is evident. In dogs and human subjects, the early signal that inhibits thirst and VP secretion has been related to the volume of fluid consumed, apparently detected by oropharyngeal receptors that monitor the swallowing of liquids regardless of whether water, isotonic saline, or hypertonic saline solution is consumed (Appelgren et al., 1982; Geelen et al., 1984; Smith \& Stricker, 2005; Thrasher et al., 1981). However, recent experiments indicate that early inhibition of VP secretion in rats is not mediated by oropharyngeal receptors (Huang et al., 2000; Stricker \& Hoffmann, 2005) because plasma VP levels (pVP) were not affected either when dehydrated rats ingested isotonic saline or when water was consumed but drained from the stomach through an open gastric fistula (Stricker

\& Hoffmann, 2005). In contrast, water ingested normally by thirsty rats initiated a rapid decline in $\mathrm{pVP}$ that began while systemic plasma $\mathrm{Na}^{+}$concentrations (pNa) still were elevated (Huang et al., 2000; Stricker \& Hoffmann, 2005), suggesting that the inhibitory effect was not mediated by cerebral osmoreceptors but by a potent presystemic stimulus, related to the composition of ingested fluid, that might arise from osmo- or $\mathrm{Na}^{+}$-receptors in the viscera (Baertschi \& Pence, 
1995; Morita et al., 1997). Furthermore, the signal that terminated an initial bout of water consumption occurred a few minutes later, in association with a reduction of systemic pNa but continued plasma volume deficits (Stricker \& Hoffmann, 2005). Because the intake of isotonic saline also ceased after similar volumes were consumed, without any associated change in $\mathrm{pNa}$ (Stricker \& Hoffmann, 2005), these observations allow the hypothesis that thirst in rats is inhibited by signals related to the volume of ingested fluid rather than to its composition. The present experiments tested this hypothesis by determining whether similar amounts of fluid were consumed by dehydrated rats given water or various $\mathrm{NaCl}$ solutions to drink. The results indicated that they were. Accordingly, additional experiments determined whether the volumes consumed were closely correlated with a physiological effect of fluid ingestion that might have provided a stimulus for inhibiting thirst. The focus of these experiments was on the volumes of ingested fluid in the stomach and small intestine when the initial drinking bout stopped.

\subsection{METHODS}

\subsubsection{Animals}

Adult male Sprague-Dawley rats (300-370 g; Harlan Laboratories) were housed singly in cages in the Biomedical Research Facility at Florida State University (experiment 2.2.3) or in the Department of Neuroscience at the University of Pittsburgh (experiments 2.2.4, 2.2.5, and 2.2.6).

Both colony rooms were maintained at a constant temperature $\left(22-23{ }^{\circ} \mathrm{C}\right)$ and with a fixed light-dark cycle (lights off from 7 p.m. to 7 a.m.). All rats had $>1$ wk of ad libitum access to pelleted laboratory chow (5001, Purina) and tap water before experiments began. 


\subsubsection{Experimental Protocols}

Experimental protocols were approved by the Institutional Animal Care and Use Committees of Florida State University and of the University of Pittsburgh.

\subsubsection{Effects of overnight water deprivation on fluid ingestion.}

Eight rats were given ad libitum access to Purina chow powder and water for 1 wk to accustom them to the special cages in which the behavioral measurements were made (Smith, 2000). On the front of these cages a $4 \times 4-\mathrm{cm}$ opening had been made to accommodate a jar containing powdered food. The water bottle was supported by a rack on the back of the cage. The drinking spout was recessed $\sim 0.5 \mathrm{~cm}$ from the cage, and the rat had access to water by licking through a slot in the cage wall. Licks on the drinking spout activated a contact circuit and were transmitted to a microprocessor and recorded in consecutive 6-sec time bins throughout the 1-h sessions. Experimental observations were made during a 20-day period in which rats were deprived of fluid each night from 5 p.m. to 9 a.m. On the following morning a 1-h drinking session began. Prior to this session, the food was removed and a fresh solution was made available. Deionized water was available to the dehydrated rats during the drinking sessions on Days 1-4. Over the next 16 days the bottle contained a $\mathrm{NaCl}$ solution. Specifically, each rat was given $0.05 \mathrm{M} \mathrm{NaCl}$ solution to drink on Days 5-8, $0.10 \mathrm{M} \mathrm{NaCl}$ solution on Days 9-12, $0.15 \mathrm{M} \mathrm{NaCl}$ solution on Days 13-16, and 0.20 M NaCl solution on Days 17-20. At the end of the 1-h sessions, food was returned to the cages and the drinking fluid remained available until 5 p.m., when the deprivation period began again. 
For each animal on each day, the volume of fluid consumed during the 1-h test session was obtained by weighing the bottle before and after the session; the difference (in g) was interpreted as the volume ingested (in ml). Intakes at intermediate times were computed by multiplying the ingested volume by the number of licks at each time-segment of interest (i.e., 5, $10,15,20,30 \mathrm{~min}$ ) and then dividing that product by the number of licks in each session. Note that these computations assumed that the volume consumed per lick was constant throughout the test session. Results presented are for intakes on the fourth day of exposure to each fluid (i.e., on Days 4, 8, 12, 16, and 20).

\subsubsection{Effects of urinary excretion on fluid ingestion in dehydrated rats}

Rats were maintained in commercial metabolism cages to determine whether urinary excretion influenced fluid ingestion. Intakes by dehydrated rats $(n=7)$ were not monitored electronically but were recorded manually $( \pm 0.1 \mathrm{ml})$. Urine was collected in calibrated tubes $( \pm 0.1 \mathrm{ml})$ at 30 and $60 \mathrm{~min}$ of the test session, and its $\mathrm{Na}^{+}$concentration was measured $( \pm 1 \mathrm{mEq} / \mathrm{L})$ using a sodium-sensitive electrode (Beckman Coulter, Synchron EL-ISE model 4410, Brea, CA).

\subsubsection{Effects of initial fluid ingestion on gastrointestinal tract and plasma}

The experiment was designed to determine the distribution of ingested fluid in the gastrointestinal tract and blood of rats at the end of the initial drinking bout. In experiment 2.2.3, we found that rats drank steadily for 5-10 min after overnight water deprivation regardless of whether water or $0.05-0.20 \mathrm{M} \mathrm{NaCl}$ solution was consumed. Thus, we focused our attention on the effects of fluid ingestion for varying periods up to $10 \mathrm{~min}$. 
On three successive days, 58 rats were adapted to a 16-h period of fluid deprivation (5:30 p.m. to 9:30 a.m.) followed by access to the same one of five fluids for $8 \mathrm{~h}$. The fluids were tap water, $0.05 \mathrm{M}, 0.10 \mathrm{M}, 0.15 \mathrm{M}$, or $0.20 \mathrm{M} \mathrm{NaCl}(n=12,8,7,17,14$, respectively). As in experiment 1 , food was accessible continuously except during the first hour of these 8-h sessions. On the fourth day, drinking fluid again was removed at 5:30 p.m. The following morning, at 9:30 a.m., food was removed from the cages, burettes containing one of the five fluids became available, and the room lights were dimmed to encourage drinking. The drinking fluid was colored with a dark green food dye (McCormick \& Co., Hunt Valley, MO) that permitted the ingested fluid to be readily visible in the small intestine (see below). The drinking test was terminated in one of two ways. Some rats were allowed to drink until they paused for $10 \mathrm{sec}$ and moved away from the drinking tube (thereby suggesting that they were not likely to resume drinking soon; Hatton \& Bennett, 1970), whereas other rats were allowed to drink for variable amounts of time $(15-225 \mathrm{sec})$ before being interrupted by the experimenter. The latter animals were used to provide information on the fate of ingested fluid before the cessation of the initial drinking bout. In either case, rats were sacrificed by decapitation within $10 \mathrm{sec}$ after the drinking test ended, and fluid intakes $( \pm 0.1 \mathrm{ml})$ and time spent drinking $( \pm 1 \mathrm{sec})$ were recorded.

Trunk blood was collected in ice-cold heparinized tubes (143 USP sodium heparin; Becton Dickinson, Franklin Lakes, NJ) and kept on ice until stomachs and intestines were obtained. The abdomen was opened and hemostats were placed at the junction of the stomach with the pylorus, at the junction of the stomach with the esophagus, and at the most distal site of visible dye in the small intestine, in that order. This portion of the surgical procedure took less than 2 min. Each stomach was removed from the carcass, the intestinal distance containing the dye was measured $( \pm 1.5 \mathrm{~cm})$, and the intestine was removed. The excised tissues were stripped 
of adhering blood vessels and connective tissue, and the stomach contents and small intestines were placed in separate beakers. The beakers were covered with Parafilm until they were placed in an oven and dried to constant weight at $60^{\circ} \mathrm{C}$ for $1-2$ days. Finally, the blood was centrifuged $\left(10,000 \times \mathrm{g}\right.$ for $5 \mathrm{~min}$ at $\left.4^{\circ} \mathrm{C}\right)$, plasma was harvested, pNa was measured $( \pm 1 \mathrm{mEq} / \mathrm{L})$ using the sodium-sensitive electrode mentioned above, and plasma protein concentration was measured $( \pm 0.1 \mathrm{~g} / \mathrm{dl})$ using a refractometer.

To summarize, our goal was to analyze in each of 58 rats all blood samples for plasma concentrations of $\mathrm{Na}^{+}$and protein, gastric chyme and small intestine (separately) for dry matter and water, and intestinal distance traversed by the ingested fluid. These analyses sum to a total of 406 individual measurements, of which 14 were lost due to procedural errors.

\subsubsection{Distribution of ingested fluid at various times after fluid ingestion}

Dehydrated rats were allowed to drink water $(n=8), 0.15 \mathrm{M} \mathrm{NaCl}(n=6)$, or $0.20 \mathrm{M} \mathrm{NaCl}(n=$ 6) until they stopped (after 5-8 min), at which time the drinking tube was removed. These rats were sacrificed by decapitation 15, 30, 45, or $60 \mathrm{~min}$ after fluid ingestion started. Using the procedures described in experiment 2.2.5, plasma concentrations of $\mathrm{Na}^{+}$and protein were measured in each blood sample, the amounts of dry matter and water were determined both in gastric chyme and small intestine, and the distance traversed by the ingested fluid in the small intestine was recorded. None of these 140 individual measurements were lost.

Finally, 6 additional rats, not deprived of water, were sacrificed and blood samples were taken in order to obtain control values of plasma $\mathrm{Na}^{+}$and protein concentrations, for purposes of comparison with the values from the various dehydrated groups. None of these 12 individual measurements were lost. 


\subsubsection{Calculations}

Gastric emptying was computed as the difference between the measured fluid intake and the estimated amount of ingested fluid that remained in the stomach, and was expressed as a percentage of the intake. In order to estimate the amount of ingested fluid that remained in the stomach, it was necessary to distinguish that fluid from water already present in the gastric chyme. To address this issue, we evaluated the gastric chyme of water-deprived rats not allowed access to drinking fluid and found that a consistent amount of water was associated with dry matter. Specifically, 12 other rats were trained as above but on the test day they were denied access to drinking water before they were decapitated; their blood, stomachs, and small intestines were removed and treated as described above. Based on a post-hoc evaluation of the obtained data, two scatter plots of the stomach liquids of individual animals (in ml, on the $y$-axis) expressed as a function of stomach solids (in g, on the $x$-axis) were prepared, one from rats whose gastric solids were $<0.60 \mathrm{~g}(n=6)$ and one from rats whose gastric solids were $>0.60 \mathrm{~g}(n$ =6). The associated trendlines, $y=1.3534 \mathrm{x}+0.2941(r=0.99, P<0.001)$ and $y=0.887 \mathrm{x}+$ 0.6676 ( $r=0.92, P<0.001$ ), respectively, were used to correct for the amount of fluid associated with gastric solids in each rat tested. That amount was subtracted from the observed water content of the chyme of rats allowed to drink in order to compute the volume of ingested water that had not yet emptied from the stomach. Forty-two dehydrated rats in experiment 2.2.5 had $<0.60$ g of dry matter in their stomachs whereas 16 had $>0.60 \mathrm{~g}$; thus, the "corrected" volumes subtracted from measured gastric water were, at most, only $1.1 \mathrm{ml}$ or $1.8 \mathrm{ml}$, respectively. Note that these calculations assumed that food residues present in gastric chyme at the start of the drinking test remained in the stomach during the brief period of testing. 


\subsubsection{Statistical Analysis}

All data are presented in scatter plots or as mean \pm SE values. Statistical reliability of observed differences in ingestive behavior was determined by using matched t-tests of mean values. Regression equations were calculated by the method of least squares. $P<0.05$ was considered to be statistically significant.

\subsection{RESULTS}

\subsubsection{Effects of overnight water deprivation on fluid ingestion}

After $16 \mathrm{~h}$ of water deprivation, rats drank more or less continuously during the first 5-10 min that water or $\mathrm{NaCl}$ solution was accessible. Neither the mean amounts consumed in this first drinking bout (range: 7.7 - $9.8 \mathrm{ml}$ ) nor the latencies to initiate a second bout (range: 10.3 - 24.6 min) differed significantly as a function of which fluid was consumed (Table 1). Cumulative intakes of the five fluids at 5, 10, 15, and 20 min of the test session were not statistically significant from one another (Fig. 1). During the remainder of the 1-h test session, rats consumed little when they drank water or $0.05 \mathrm{M} \mathrm{NaCl}$ and more when they drank $0.10 \mathrm{M}, 0.15$ M, or $0.20 \mathrm{M} \mathrm{NaCl}$ (Fig. 1; all Ps <0.05). As shown in Table 1, the mean number of additional drinking bouts ranged from 1.1 (when rats drank water) to 3.4 (when they drank $0.15 \mathrm{M} \mathrm{NaCl}$ ). The mean amounts consumed in those additional drinking bouts ranged from $0.9 \mathrm{ml}$ (of water) to $3.7 \mathrm{ml}$ (of $0.20 \mathrm{M} \mathrm{NaCl}$ ) and increased progressively in proportion to the concentration of the ingested fluid ( $r=0.97, P<0.001$ ). In other words, when water was available rats returned to drink least often and drank the smallest volumes in these later bouts, whereas when $0.15 \mathrm{M}$ or 
0.20 $\mathrm{M} \mathrm{NaCl}$ was available rats returned to drink most often and drank the largest volumes of fluid in those bouts.

\subsubsection{Effects of urinary excretion on fluid ingestion in dehydrated rats}

A separate group of dehydrated rats was studied similarly but this time excreted urine was collected during the 1-h test session and its volume and $\mathrm{Na}^{+}$concentration was measured. The animals drank an average of 8-12 $\mathrm{ml}$ in $15 \mathrm{~min}$ and $12-17 \mathrm{ml}$ in $60 \mathrm{~min}$, as in experiment 2.2.3, yet few rats voided any urine. Rats drinking $0.20 \mathrm{M} \mathrm{NaCl}$ excreted urine in the greatest volumes and highest $\mathrm{Na}^{+}$concentrations $(0.5 \pm 0.2 \mathrm{ml}$ in $60 \mathrm{~min}, 275 \pm 12 \mathrm{mEq} / \mathrm{L})$.

\subsubsection{Effects of initial fluid ingestion on gastrointestinal tract and plasma}

These investigations focused on drinking that occurred during the first 10 min or less of fluid access after overnight deprivation. Seventeen of the 58 rats studied were sacrificed as soon as they ended the first drinking bout whereas the others were interrupted at predetermined times and sacrificed earlier ( $<5$ min after they began to drink). Fig. 2 displays a scatter plot of cumulative intakes of each animal as a function of time spent drinking, and indicates that the dehydrated rats drank at a similar rate over time regardless of which fluid was ingested.

The gastric chyme usually contained very little dry matter at the start of the experiment. More specifically, 38 dehydrated rats had 0.10 - $0.60 \mathrm{~g}$ of dry matter in the chyme; 6 of these rats were not given access to drinking fluid $(0.34 \pm 0.06 \mathrm{~g})$ while the other 32 rats drank water or saline $(0.36 \pm 0.03 \mathrm{~g} ; P=\mathrm{ns})$. Individual values of gastric water in the latter animals are displayed in Fig. 3A as a function of intake. It is apparent that the gastric fluid volumes of these rats correlated well with intakes regardless of which fluid was consumed $(r=0.88, P<0.001)$. 
Gastric emptying of the ingested fluid was similar whether rats drank water or $0.05 \mathrm{M} \mathrm{NaCl}$ (49 $\pm 3 \%$ ), $0.10 \mathrm{M}$ or $0.15 \mathrm{M} \mathrm{NaCl}(43 \pm 3 \%)$, or $0.20 \mathrm{M} \mathrm{NaCl}$ (48 $\pm 4 \%$ ), and it was not correlated with gastric dry matter $(r=0.10, P=\mathrm{ns})$. In contrast, the gastric fluid volumes were uniformly low in 10 rats with gastric dry matter $<0.10 \mathrm{~g}$ (Fig. 3B), indicating that a larger portion of the ingested fluid emptied from the stomach while the rats were drinking (75 $\pm 3 \%$; $P<0.001$ in comparison to rats with gastric dry matter of 0.10-0.60 g). Conversely, the gastric fluid volumes in 16 rats with gastric dry matter $>0.60 \mathrm{~g}$ were consistently higher than those in rats with gastric dry matter of $0.10-0.60 \mathrm{~g}$, for a given level of fluid intake (Fig. 3B), and they were highly correlated with intakes regardless of which fluid was consumed $(r=0.96, P<0.001)$.

Portions of the small intestine proximal to the stomach always were visibly swollen with dyed fluid. Fig. 4 displays a scatter plot of the dye-colored fluid volume in the small intestine as a function of fluid intake in individual rats whose gastric solids were $>0.10 \mathrm{~g}$. Intestinal fluid volumes were exponentially related to fluid intakes regardless of whether the animals drank water or saline ( $r=0.95 ; P<0.001)$. These intestinal fluid volumes were inversely correlated with gastric fluid volumes when both were expressed as percentages of fluid intake (rats drinking water or $0.05 \mathrm{M}, 0.10 \mathrm{M}$, or $0.15 \mathrm{M} \mathrm{NaCl}, r=-0.66, P<0.001$ ); in other words, when more ingested fluid remained in the stomach, less was found in the small intestine, and vice versa. Fig. 5 displays the sum of the fluid volumes in the stomach and small intestine (i.e., gastrointestinal fill, or "GI fill”) of individual animals as a function of fluid intake; these variables were highly correlated with one another regardless of which fluid was consumed, how much was consumed, or how the ingested fluid was distributed in the stomach and small intestine $(r=0.96, P<0.001)$. Similarly, the sums of the fluid volumes in the stomach and small intestine 
of individual animals also were highly correlated with their intakes of $0.20 \mathrm{M} \mathrm{NaCl}(r=0.99, P$ $<0.001$ ), but the regression line was steeper than the line associated with data from the other rats.

Fig. 6 presents a scatter plot of the intestinal distances (past the pylorus) that were colored by the green dye in the drinking fluid, as a function of the volume of ingested fluid in that segment of the small intestine. The logarithmic relation between these two variables was statistically significant ( $r=0.84, P<0.001$ ), and no difference between rats consuming water and saline was apparent. Collectively, the data in Figs. 2, 4, and 6 indicate that dye was visible in the small intestine soon after the onset of drinking and quickly traversed great distances, so it was deep within the intestine by the time drinking ceased.

Fig. 7 presents a scatter plot of the calculated mean distension (in $\mathrm{ml} / \mathrm{cm}$ ) of the dyecolored segment of small intestine as a function of luminal fluid volume in that segment. The significant linear relation between these two variables indicated that distension increased and did so in proportion to intestinal volume $(r=0.85, P<0.001)$. No differences were observed between rats that drank water and rats that consumed saline.

When dehydrated rats were sacrificed soon after an initial drinking bout (for $\geq 5 \mathrm{~min}$ ), the composition of the ingested fluid was found to influence the pNa but not the plasma protein concentration. As indicated in Table 2, the pNa in the 7 rats consuming water, $0.05 \mathrm{M}$, or 0.10 $\mathrm{M} \mathrm{NaCl}$ was significantly lower than the pNa in the 10 rats consuming $0.15 \mathrm{M}$ or $0.20 \mathrm{M} \mathrm{NaCl}$ or the pNa in the 10 rats that were denied access to drinking fluid (both $P \mathrm{~s}<0.01$ ). In contrast, the volumes consumed by rats ingesting water or hypotonic saline were not significantly different from values of rats ingesting isotonic or hypertonic saline. When drinking was interrupted after $\sim 3 \mathrm{~min}$, the pNa of rats consuming water or hypotonic saline $(144.4 \pm 0.2$ $\mathrm{mEq} / \mathrm{L}$ after rats drank $4.7 \pm 0.5 \mathrm{ml}$ in $2.7 \pm 0.3 \mathrm{~min}, n=16$ ) also were significantly lower than 
the values of dehydrated rats not allowed access to drinking fluid $(148.3 \pm 0.5 \mathrm{mEq} / \mathrm{L}, n=10, P$ $<0.001)$ and of rats consuming isotonic or hypertonic saline $(146.1 \pm 0.7 \mathrm{mEq} / \mathrm{L}$ after rats drank $4.5 \pm 0.5 \mathrm{ml}$ in $2.9 \pm 0.2 \mathrm{~min}, n=12, P<0.05)$.

\subsubsection{Distribution of ingested fluid at various times after fluid ingestion}

Additional dehydrated rats were sacrificed at various times after an initial drinking bout of water, $0.15 \mathrm{M} \mathrm{NaCl}$, or $0.20 \mathrm{M} \mathrm{NaCl}$. The amounts of ingested fluid found in the stomach and small intestine diminished rapidly with time in each case (Fig. 8). Gastric emptying of water or $0.15 \mathrm{M}$ $\mathrm{NaCl}$ was $90-100 \%$ by $30-45 \mathrm{~min}$, but it was somewhat slower in rats that drank $0.20 \mathrm{M} \mathrm{NaCl}$ (80-90\% by $45-60 \mathrm{~min}$ ). The ingested fluid traveled $90-105 \mathrm{~cm}$ into the small intestine by 30 $\min ;>60 \%$ of ingested water or $0.15 \mathrm{M} \mathrm{NaCl}$ was absorbed by then, whereas absorption of 0.20 $\mathrm{M} \mathrm{NaCl}$ was slower (60\% by the end of the 60 -min test period). As shown in Table 2, plasma $\mathrm{Na}^{+}$was significantly reduced after 15-60 min when rats drank an initial bout of water (140.5 \pm $0.4 \mathrm{mEq} / \mathrm{L}$, in comparison with $143.7 \pm 0.9 \mathrm{mEq} / \mathrm{L}$ in non-deprived control rats, $n=6, P<0.02$ ), but it remained elevated when they drank the saline solutions $(146.2 \pm 0.6 \mathrm{mEq} / \mathrm{L}, P<0.05$ in comparison with non-deprived control rats). In contrast, plasma protein concentrations were reduced to levels that were slightly above normal $(6.4 \pm 0.1,6.3 \pm 0.1 \mathrm{~g} / \mathrm{dl}$, respectively, in comparison with $6.1 \pm 0.1 \mathrm{~g} / \mathrm{dl}$ in non-deprived control rats, $n=6 ; P=\mathrm{ns}$, ns, respectively).

\subsection{DISCUSSION}

Water deprivation increases thirst in rats due to increased plasma osmolality (pOsm) and decreased blood volume (Ramsay et al., 1977). The reported thresholds for these effects are a 1- 
2\% increase in pOsm (Fitzsimons, 1963) and a 5-7\% decrease in blood volume (Stricker, 1968).

Both thresholds were exceeded in the present studies; specifically, there was a $5 \%$ increase in $\mathrm{pNa}$ and a 15\% decrease in plasma volume (estimated from the changes in plasma protein concentration; Stricker, 1968) in the water-deprived rats. These two changes presumably had an additive effect in stimulating thirst (Stricker, 1969). In consequence, the water-deprived rats drank as soon as fluid was returned to their cages and they did so at a fast and steady rate for 5-8 $\min$.

The main goal of the present studies was not to determine why the dehydrated rats started to drink but why they stopped. The results displayed in Fig. 1 indicate that the initial drinking bout ended within 10 min whether water or $\mathrm{NaCl}$ solution was consumed. When the rats drank water, it was noteworthy that $\mathrm{pNa}$ had returned to normal by the time they stopped drinking (Table 1), in confirmation of previous findings (Hall \& Blass, 1975; Hatton \& Bennett, 1970; Stricker \& Hoffmann 2005). However, pProt had not changed at this time; that is, the dehydrated animals remained hypovolemic, as expected since most of the ingested water that emptied from the stomach and was absorbed should have entered tissue cells by osmosis. Thus, the rats did not stop drinking due to the removal of all excitatory signals for thirst but due to some inhibitory signal that prevailed despite continued plasma volume deficits. The inhibition of thirst that occurs when hypovolemic rats drink water is a well-known phenomenon that has been attributed to osmotic dilution of body fluids (Stricker, 1969). However, such inhibition did not appear to be a factor in the present study because osmotic dilution of systemic blood was not evident at the time rats stopped drinking water (although it did occur later; Table 2, also Hall \& Blass, 1975; Hatton \& Bennett, 1970). Furthermore, the dehydrated rats ended their initial drinking bout at more or less the same time regardless of which fluid they consumed (Fig. 1), 
and no decrease in pNa was expected or observed in rats that drank $0.15 \mathrm{M}$ or $0.20 \mathrm{M} \mathrm{NaCl}$ solution. Thus, in considering the signals that provided the inhibition of thirst, we focused our considerations on the volume of the ingested fluid rather than its concentration.

Thrasher, Ramsay and colleagues (1981) have reported that fluid volume ingested by dehydrated dogs is sensed by oropharyngeal receptors that monitor swallowing. These signals inhibited intake after a few minutes of drinking despite the fact that systemic pOsm was not restored until 30 min after water consumption began. Oropharyngeal signals also provided rapid inhibition of the complementary secretion of VP that occurred during dehydration (Thrasher et al., 1981). Subsequent studies extended these latter observations to other experimental subjects including sheep, monkeys, and humans (Arnauld \& DuPont, 1982; Blair-West et al., 1985; Geelen et al., 1984; Seckl et al., 1986). However, we recently reported that the same mechanism does not operate in rats (Huang et al., 2000; Stricker \& Hoffmann, 2005). Dehydrated rats, like dogs, began to reduce plasma levels of VP after a few minutes of water consumption, but unlike dogs they did not do so when the ingested fluid drained through an open gastric fistula (Stricker \& Hoffmann, 2005). In further contrast with dehydrated dogs, plasma levels of VP were not rapidly reduced when thirsty rats consumed isotonic $\mathrm{NaCl}$ solution (Huang et al., 2000; Stricker \& Hoffmann, 2005). These findings complement previous reports that drinking is quickly inhibited when a gastric water load is given to dehydrated rats (Adolf, 1950), and that dehydrated rats with an open gastric fistula continue to drink water for many minutes (Davis et al., 2002; Waldbillig \& Lynch, 1979), unlike dehydrated dogs (Adolf, 1950; Thrasher et al, 1981).

The inhibition of thirst that occurs when dehydrated animals drink water was a subject of considerable inquiry before Thrasher et al. (Thrasher et al, 1981) reported their seminal findings. Rats were the experimental subject in many of those earlier studies, most of which focused on 
the roles of gastric distension and systemic hydration in inhibiting water ingestion by dehydrated rats (Blass \& Hall, 1976). For example, observations that water consumption increased when a closed pyloric cuff precluded gastric emptying (Davis \& Sayler, 1997; Hall \& Blass, 1977) suggested that drinking was inhibited under normal conditions by gastric distension together with a signal related to the low osmolality or $\mathrm{Na}^{+}$concentration of the fluid that entered the small intestine (Baertschi \& Pence, 1995; Morita et al., 1997). But why do dehydrated rats stop drinking $0.15 \mathrm{M} \mathrm{NaCl}$, when osmotic dilution cannot be a factor? The present results suggest that the inhibitory signal was not provided by gastric distension alone because ingested fluid emptied from the stomach so rapidly; indeed, almost half of it had left the stomach while the dehydrated rats were drinking. Most of that emptied fluid had not yet been absorbed and thus was still present in the small intestine when the animals stopped drinking. Consequently, the sum of gastric and small intestinal volumes after the initial drinking bout was well-correlated with fluid intake (Fig. 6). These results allow the hypothesis that the signal inhibiting the initial bout when rats drank $0.15 \mathrm{M} \mathrm{NaCl}$ was provided by distension of both the stomach and small intestine. That same signal presumably contributed to inhibition when rats drank the more dilute solutions, together with an additional inhibitory signal related to the dilute concentration of the fluid passing through the small intestine.

Distension of the stomach and small intestine has been proposed to contribute an inhibitory stimulus in the control of food intake when rodents consume liquid diet (Fox et al., 2001; Schwartz et al., 1999). Consistent with that hypothesis and of clear relevance to our present proposal, stretch receptors on the wall of the stomach and the proximal small intestine allow the detection of distension (Mathis et al., 1998; Wang \& Powley, 2000). Because vagal and spinal afferents from these sites project to the nucleus of the solitary tract (NTS) and area 
postrema (Norgren \& Smith, 1988), it seems plausible that these peripheral nerves project to the same cells (or to neurally linked cells) in the caudal brain stem and in that way contribute to an integrated message. If so, then damage to the afferent fibers or to their projection sites should remove this inhibition and thereby increase fluid ingestion in an initial bout of drinking by thirsty rats. Reports published previously are consistent with this hypothesis. Thus, after systemic injection of capsaicin to destroy visceral sensory nerves with unmyelinated axons, rats showed increased drinking responses to treatments that increase pOsm or decrease plasma volume (Curtis \& Stricker, 1997). A similar increase in water consumption has been reported in thirsty rats with aspiration lesions of the area postrema and subadjacent NTS (Curtis et al., 1996). Note that such results would not be expected if cessation of thirst was mediated solely by cerebral osmoreceptors that detected dilution of systemic blood.

The volume of ingested fluid found in the small intestine increased in proportion to intake regardless of which fluid was consumed. It quickly traveled deep into the small intestine but the distance reached an asymptote at $60-80 \mathrm{~cm}$, which is about two-thirds of the full length of the small intestine in these rats. Presumably the initial phase of this logarithmic function was due to the propulsion of fluids into the small intestine that resulted from gastric contractions, whereas that high rate of movement slowed in part due to resistance encountered as the luminal fluid approached the ileal-cecal sphincter. In addition, the distensible intestinal wall was visibly expanded by the increased luminal fluid, which would slow intestinal transit. The equation for the regression line in Fig. 7, $y=0.010 x+0.015$, indicates that the mean distension of the dyecolored segment of small intestine doubled when $1.5 \mathrm{ml}$ of volume entered the intestine. That volume was associated with intakes of $\sim 8 \mathrm{ml}$ (Fig. 4), which were the amounts consumed by dehydrated rats after drinking for $\sim 5$ min (Fig. 2). 
After a large initial drinking bout, dehydrated rats consumed a few smaller bouts of additional fluid when they drank the more concentrated $\mathrm{NaCl}$ solutions instead of water or 0.05 $\mathrm{M} \mathrm{NaCl}$. Note that $8 \mathrm{ml}$ of $0.20 \mathrm{M} \mathrm{NaCl}$, when fully equilibrated with body fluids, is estimated to raise pOsm in these dehydrated rats by only $\sim 1 \mathrm{mOsm} / \mathrm{kg}$, which should not make them much thirstier. But what makes them less thirsty and thereby limits their fluid consumption? Since none of these rats excreted much urine during the 60 -min period of observation, and plasma $\mathrm{Na}^{+}$ values were little changed after $15-60$ min of drinking $0.15 \mathrm{M}$ or $0.20 \mathrm{M} \mathrm{NaCl}$ (Table 2), it seems likely that their fluid intakes were not influenced by renal function; in fact, previous studies have shown that dehydrated rats drinking $0.15 \mathrm{M} \mathrm{NaCl}$ do not excrete concentrated urine until later (Hall \& Blass, 1975; Stricker et al., 2001). Instead, the present results suggest that an early inhibition of thirst occurred due to increased gastrointestinal distension when dehydrated rats drank $0.10-0.20 \mathrm{M} \mathrm{NaCl}$, and that this inhibition diminished during the 1-h test period as ingested fluid was gradually absorbed from the small intestine, which presumably allowed drinking to resume intermittently.

To summarize, dehydrated rats did not continuously ingest fluid until they were fully rehydrated. The early inhibitory signal appears to be related to the volume of ingested fluid rather than to its composition. This volume was highly correlated with the fluid volumes found in the stomach and small intestine of rats when they stopped drinking an initial bout. Thus, gastrointestinal distension might plausibly provide an early signal inhibiting thirst in dehydrated rats. According to this hypothesis, gastric emptying would not reduce this putative inhibitory signal as long as the emptied fluid remained in the small intestine. However, the movement of osmolytes into the small intestine can rapidly affect body fluid osmolality, which should decrease the excitatory signals of thirst and thereby limit additional fluid consumption. For 
example, when dehydrated rats drank water or $0.05 \mathrm{M} \mathrm{NaCl}$, the relatively large osmotic component of the excitatory signal was reduced as body fluids were diluted. Conversely, when dehydrated rats drank $0.15 \mathrm{M}$ or $0.20 \mathrm{M} \mathrm{NaCl}$, absorption of ingested fluid from the small intestine apparently increased plasma volume and thereby reduced the relatively small hypovolemic component of the excitatory signal. In the latter situation, the rats presumably resumed drinking as GI fill diminished because the large excitatory signal associated with increased pOsm was not affected rapidly. Subsequent investigations must further evaluate whether observed correlations between fluid ingestion and postingestional variables reflect causal relations as proposed.

\subsection{PERSPECTIVE}

Drinking by dehydrated dogs generates an early oropharyngeal signal that inhibits both thirst and VP secretion (Thrasher et al., 1981). The present results, together with earlier observations (Stricker \& Hoffmann, 2005), indicate that the same arrangement does not apply to dehydrated rats. There is an early inhibition of thirst and VP secretion in rats, but the same signal does not inhibit both responses nor is either signal oropharyngeal. This difference between the two species may result from the fact that rats drink relatively slowly but empty ingested fluid from their stomachs relatively quickly in comparison to dogs. Note that the early inhibition of VP secretion in dehydrated rats, generated once the ingested fluid reaches the small intestine, is more appropriately based on the concentration of the ingested fluid rather than its volume because the fluid need of these animals is largely osmoregulatory. It will be interesting to determine whether 
early signals inhibit VP secretion and thirst in rats during hypovolemia, and if so, whether they are based on the volume or composition of ingested fluid.

It will also be interesting to determine whether pre-systemic signals inhibit salt appetite in rats, which is another important homeostatic response to hypovolemia (Stricker \& Jalowiec, 1970). In this regard, recent studies have indicated that when hypovolemic rats were allowed access to water, $0.15 \mathrm{M} \mathrm{NaCl}$, or $0.30 \mathrm{M} \mathrm{NaCl}$ in one-bottle tests, intake appeared to be inhibited by two variables, altered pOsm (when the rats drank water or $0.30 \mathrm{M} \mathrm{NaCl}$ ) and GI fill (Smith \& Stricker, 2005). Those preliminary findings, together with the present data on fluid ingestion after dehydration, collectively support the hypothesis that GI fill inhibits drinking in rats regardless of whether thirst or salt appetite motivates intake and regardless of what fluid the rats consume. 


\subsection{GENERAL DISCUSSION}

The general goal of the current work in the laboratory is to determine whether rats utilize presystemic signals to influence ingestive behaviors and hormone secretion important to the maintenance of body fluid homeostasis. This report shows that there is a presystemic signal for the inhibition of thirst, and suggests that it is tightly correlated with distension of the stomach and proximal small intestine (“GI fill”).

Previous work had shown that dehydrated dogs show a simultaneous inhibition of thirst and vasopressin (VP) secretion before any changes in the osmolality of systemic blood had occurred and independently of the osmolality of the fluid being ingested. In a seminal series of reports, Ramsay, Thrasher, and colleagues showed that the swallowing pattern that accompanies drinking generates a neural signal from the oropharynx that is responsible for the inhibition of VP secretion and thirst. This inhibition was associated with the act of drinking and swallowing fluid, and persisted for 15-20 minutes until enough of the ingested fluid had been absorbed to influence body fluid osmolality (Thrasher et al., 1981, 1987; Appelgren et al., 1991).

In a recently published article (Stricker \& Hoffmann, 2005) we showed that dehydrated rats also use a presystemic signal for the inhibition of VP secretion. However, unlike the results in dogs, the rats' presystemic signal does depend on the concentration of ingested fluids. These findings are consistent with the original observation that rats infused with hypertonic saline show

a rapid, presystemic inhibition of VP secretion when they drank water but not when they drank 
isotonic saline (Haung et al., 2000). In fact, the osmolality of systemic blood did not change in these animals, even when they drank water, because the infusion of hypertonic saline was continued during the testing period and therefore the impact of ingested water to dilute body fluids was buffered. Together with the data from the present report, these findings show that rats do utilize presystemic signals for the inhibitory control of thirst and VP secretion. However, unlike dogs, the nature of these presystemic signals in rats differs both in quality and in time course. Specifically, the inhibition of VP secretion in rats takes place early in the initial drinking episode and is dependent on the postgastric detection of water. In contrast, as indicated in the present report, the presystemic inhibition of thirst in rats arises after several minutes of drinking and is not dependent on the concentration of the ingested fluid. Those observations led us to consider potential stimuli that were related to the volume of the ingested fluid. We found that neither distension of the stomach nor distension of the small intestine alone correlated well with the volume of fluid ingested, whereas the combined distension of the stomach and small intestine was very well-correlated with intake and was consistent between animals that voluntarily ceased drinking, regardless of the concentration of ingested fluid.

Because of this strong correlation we proposed that the distension signal arising from GI fill provides the presystemic inhibition of drinking behavior. However, additional experiments will have to be conducted to determine whether the relation between these two variables is causal. There are several kinds of experiments that could test this hypothesis. One approach would involve the examination of models of thirst other than water deprivation in order to determine whether thirst is consistently inhibited by the same amount of GI fill. Water deprivation produces a mixed signal for thirst involving cellular dehydration and plasma volume deficits (Ramsay et al., 1977), and each of those separate components can be studied 
independently. For example, ip injection of hypertonic saline can be used to increase pOsm and activate cerebral osmoreceptors whereas sc injection of polyethylene glycol can be used to produce graded degrees of hypovolemia in rats. In fact these studies have been done by others in our laboratory, and the amount of GI fill found when animals finish their first water drinking bout is similar to that which was found in this report (Smith \& Stricker, 2005; Vaughan et al., 2005).

A second approach would involve artificially generating distension signals in the GI tract, as by inflation of a balloon or infusion of isotonic saline into the stomach and/or the small intestine in dehydrated rats in order to determine whether drinking was inhibited. Many such studies have been done addressing the impact of gastric distension on food intake, but I am aware of only one investigation that addressed the inhibition of thirst. In 1997, Bardos used a balloon to distend the small intestine of rats deprived of water for $23.5 \mathrm{hr}$ and prepared with Thiry-Vella intestinal loops. He reported a small decrease in water consumption in these rats after filling the balloon with as little as $0.05 \mathrm{ml}$ of fluid. Greater volumes of filling caused greater reductions in water intake but, unfortunately, the dimensions of the balloon was not given. This omission prevents direct comparisons with the mean small intestinal distensions in the current report, but it seems plausible that $0.05 \mathrm{ml}$ or even twice that amount infused into a balloon could be comparable to the mean small intestinal distension of $0.04-0.05 \mathrm{ml} / \mathrm{cm}$ found in animals that voluntarily stopped drinking in the current report (see Fig 7). Bardos (1997) also used behavioral analysis to determine that a $0.05-0.12-\mathrm{ml}$ distension does not cause aversive behaviors in rats. As intriguing as these results are, additional studies will have to be done to assess how relevant the distension of small portions of intestine relate to the current work, in which large portions of the proximal small intestine were distended. We are currently developing a protocol in which 
isotonic saline solutions will be infused directly into the small intestine to determine its impact on drinking.

A third approach would involve preventing distension of the GI tract during drinking, or allowing distension but interfering with the communication of the distension signal from the viscera to the brain. In perfecting our protocols for our recent report on the presystemic inhibition of VP secretion, we noted that some of our pilot animals with an open gastric fistula had dye from the ingested water in their small intestine. The amount of fluid collected from these animals when the fistula was open was as much as $100 \%$ of the ingested fluid, but an average of $112 \%$ of the ingested fluid was collected via the fistula in rats in which no dye was visible in the intestine. (The additional fluid is presumed to be orogastric secretions.) We believe that many studies investigating the contribution of gastric distention in ingestive behaviors could have been altered greatly by slight variations in the placement of the fistula that allows fluids to drain from the stomach during the test. In our hands, thirsty rats show no inhibition of thirst when both gastric distension and postgastric effects of ingested fluids are removed by drinking with an open gastric fistula (Stricker \& Hoffmann, 2005).

A series of experiments are also underway in which the small intestine is surgically denervated. Provided the signal is neural as opposed to endocrine, this denervation would remove the inhibition of drinking by "GI fill” regardless of which fluid the rats drank, as well as remove the presystemic inhibition of VP secretion when dehydrated rats drank water. Preliminary data suggest that these denervated, animals do overdrink both water and isotonic saline after an overnight period of water deprivation, and that the intakes of isotonic saline are even larger than the intakes of water (Smith \& Stricker, 2006). These findings are consistent with the results of previous experiments that have interfered with neural transmission by destroying 
the projection sites of the vagus nerve in the area postrema (Curtis et al., 1996) as well as studies conducted on rats that had been pretreated with capsaicin to destroy the non-myelinated sensory nerves in the abdominal cavity (Curtis \& Stricker, 1997).

In addition to the extensive and accumulating evidence that presystemic signals can inhibit VP secretion and thirst in rats, there is also growing evidence that presystemic signals can contribute to the stimulation of these responses in rats. Kraly and colleagues (1985) showed that an intragastric intubation of hypertonic saline stimulates water intake in euhydrated rats before increases in pOsm appear. Subsequent work in our lab have used the same procedures but moved from examining the latency of thirst onset to measuring water intake after intragastric $\mathrm{NaCl}$ loads were administered to euhydrated or dehydrated rats (Stricker et al., 2001). The results indicated that the loads actually stimulated very little drinking in euhydrated rats whereas they elicited substantial water intakes in the dehydrated animals.

A limitation common to these studies is that the salt load is artificially introduced into the animals by the investigator. Recent work in the lab has attempted to overcome this limitation by having the animal self-administer the salt load. This has been accomplished by providing rats with a high-salt $(8 \% \mathrm{NaCl})$ diet. Intact rats increase water consumption during a meal of highsalt food, but the initiation of drinking occurred concurrently with increases in pNa (Stricker et al., 2003). One possible explanation is that the presystemic stimulation alone is not sufficient to induce drinking in hungry animals until there is a significant increase in pOsm. Alternatively, analyses revealed that the salt was embedded in, and emptied with, the dense gastric chyme, thereby buffering the effects of the salt load on presystemic receptors.

To circumvent this adaptive mechanism, rats that had their salivary flow surgically abolished were tested. This "desalivation" obliges the animal to drink large amounts of fluid to 
facilitate swallowing (Stricker, 1970). It was found that these desalivated animals consumed much more water when eating an $8 \% \mathrm{NaCl}$ diet than when consuming a diet containing $1 \%$ $\mathrm{NaCl}$. In fact, hungry animals given the $8 \% \mathrm{NaCl}$ diet to eat drank enough water to dilute the resulting fluid leaving the stomach to approximately an isotonic solution (Manesh et al., 2006). Creating an isotonic solution may be useful to a hungry animal by avoiding any osmotic inhibition of food intake.

There also are studies whose findings are consistent with a presystemic signal for the stimulation of VP secretion. Baertschi's lab demonstrated that pVP increases withour changes in systemic pOsm in response to the application of hypertonic fluids either to the mesenteric circulation (Baertschi \& Vallet, 1981) or to the stomach (Choi-Kwon et al., 1990). Stricker and colleagues (2002) demonstrated that pVP levels in dehydrated rats were further elevated by a gastric load of hypertonic saline before systemic pOsm increased further. I also have begun to collect data on the presystemic stimulation of VP secretion when rats self-administer a salt load via food ingestion. Hungry rats were given a mash made from high- $\mathrm{NaCl}$ diet $(8 \% \mathrm{NaCl}$ mixed 1:1 with water), which generated a chyme that had "free" liquid with a strong $\mathrm{NaCl}$ concentration that could empty more quickly than the food particles. The preliminary data suggest that VP secretion induced by eating this mash does precede any increase in systemic plasma $\mathrm{Na}^{+}$concentrations (Hoffmann \& Stricker, 2005). In combination, these studies suggest that there are presystemic signals that can stimulate both thirst and VP secretion.

In short, just as cerebral osmoreceptors apparently can stimulate or inhibit thirst and VP secretion depending on the osmolality of systemic blood, it appears that the visceral osmoreceptors have the same capacity to mediate both excitation and inhibition of the regulatory responses to changes in the osmolality of fluid emptying from the stomach. Additional work will 
allow greater clarity in characterizing the mechanisms underlying the visceral signals. For instance, the use of $\mathrm{NaCl}$ as our osmotic substance does not allow insight into whether the visceral receptors are in fact osmosensitive or are selectively sensitive to $\mathrm{Na}^{+}$. A $\mathrm{Na}^{+}$-specific receptor in the viscera would seem particularly useful to the animal in ultimately controlling systemic pOsm. We plan to begin a new series of studies using mannitol as the osmolyte emptying from the stomach to determine whether thirst and VP secretion will be stimulated.

Another obvious experimental question is, Where are the visceral osmo- (or $\mathrm{Na}^{+}$-) receptors located that may be responsible for the early inhibition of VP secretion in rats? The traditional view has been that these putative receptors are located in the hepatic portal vein (e.g., Baertschi \& Vallet, 1981). In fact, in these early studies fluids were either superfused onto portions of the visceral circulation or delivered to the stomach via a nasogastric tube. The authors concluded that the receptors were located in the walls of the hepatic portal vein. However, there is a rapid flow of flood through the portal vein in awake animals. Consequently, it would seem that receptors there could only respond to a signal large enough to affect the concentration of a large volume of blood. Furthermore, the signal would be transient unless new fluid continued to enter the small intestine. The utility of an early signal from the viscera is to bridge the time gap between ingestion and the equilibration of ingested fluids or food with body fluids, at which time the cerebral osmoreceptors could respond appropriately. It seems more plausible to postulate receptors in an area that allows for a very rapid onset of a signal, but that also provides less turbulence and therefore a more prolonged stimulation.

A receptor that interacts with the intestinal lymph would be ideally situated to transmit early visceral signals (Patrick Tso, personal communication, 2004). As food or fluid empties from the stomach, nutrients, osmoles, and water are absorbed or transported through the 
intestinal lumen and actively transported either into the blood vessels or into the adjacent lymph vessels. Lymph vessels have large pores that allow osmotic particles to enter the vessel, but there is little equilibration between or absorption across the lymph vessel back to the interstitium (unlike the small intestinal lumen). Flow is largely dependent on the influx of fluids and local muscle contraction. (The presence of one-way valves prevents back-flow.) We have begun studies designed to determine whether there are rapid, sustained decreases in the $\mathrm{Na}^{+}$ concentrations of intestinal lymph after water ingestion, and preliminary data indicate that there are. Such findings, if replicated, would support the hypothesis that a visceral osmo- or $\mathrm{Na}^{+}-$ receptor could be located in, or associated with, the lymph vessel.

In summary, this thesis work has contributed to an understanding of the presystemic signals that influence thirst and drinking behavior in rats. This work fits nicely within the context of previous work which suggested that presystemic mechanisms modulate the secretion of VP. In addition, it can serve to guide future experiments that can be designed to further clarify the mechanism by which information from the viscera is integrated by the brain, allowing for its exquisite control over the concentration of body fluids and therefore bodily functions. 


\title{
APPENDIX A
}

\author{
TABLES
}

Table 1 Intake of water or $\mathrm{NaCl}$ solution by dehydrated rats during a 1-hr test session.

$\begin{array}{lcccc} & \begin{array}{c}(\mathrm{ml}) \\ \text { Intake }\end{array} & \begin{array}{c}(\mathrm{min}) \\ \text { Latency }\end{array} & \begin{array}{c}\text { Additional } \\ \text { Bouts }\end{array} & \begin{array}{c}(\mathrm{ml}) \\ \text { Bout size }\end{array} \\ & 8.6 \pm 0.7 & 24.6 \pm 6.7 & 1.1 \pm 0.3^{\mathrm{a}} & 0.9 \pm 0.2 \\ \text { Water } & 9.0 \pm 0.6 & 20.4 \pm 4.6 & 1.4 \pm 0.2^{\mathrm{a}} & 1.5 \pm 0.3 \\ 0.05 \mathrm{M} \mathrm{NaCl} & 8.1 \pm 0.7 & 10.3 \pm 3.4 & 2.5 \pm 0.4 & 2.4 \pm 0.3 \\ 0.10 \mathrm{M} \mathrm{NaCl} & 7.5 \pm 0.6 & 17.1 \pm 6.4 & 3.4 \pm 1.0 & 2.5 \pm 0.2 \\ 0.15 \mathrm{M} \mathrm{NaCl} & 7.3 \pm 1.8 & 20.8 \pm 7.8 & 2.1 \pm 0.5 & 3.7 \pm 0.3 \\ 0.20 \mathrm{M} \mathrm{NaCl} & & & & \end{array}$

Values are $\mathrm{M} \pm \mathrm{SE}(n=8)$ for intakes (ml) in the first drinking bout, the latency (min) between the end of the first bout and the beginning of the second bout, the number of additional drinking bouts in the 1-hr test session, and the amount consumed (ml) in those additional bouts. Note that the same 8 rats were tested with each fluid. No statistically significant differences between groups were observed in the size of the first drinking bout or the latency before the second bout; those two variables were significantly correlated with one another only when the rats drank water $(r=0.70, P<0.05)$. Significant differences in the number of additional bouts 
were observed in only two comparisons, as indicated ( ${ }^{\mathrm{a}} \mathrm{P}<0.05$ in comparison with $0.10 \mathrm{M}$ $\mathrm{NaCl}$ ). In contrast, each difference between groups in the size of those additional bouts was statistically significant $(P<0.01)$ except in two comparisons, water and $0.05 \mathrm{M} \mathrm{NaCl}$, and 0.10 $\mathrm{M} \mathrm{NaCl}$ and $0.15 \mathrm{M} \mathrm{NaCl}$.

Table 2 Plasma levels of $\mathrm{Na}^{+}$and protein in dehydrated rats given nothing, water or hypotonic saline, or isotonic or hypertonic saline to drink.

\begin{tabular}{|c|c|c|c|c|}
\hline & & (min) & $(\mathrm{ml})$ & $(\mathrm{mEq} / \mathrm{L})$ \\
\hline Group & $n$ & time & intake & plasma $\mathrm{Na}^{+}$ \\
\hline
\end{tabular}

No fluid access

10

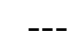

$148.3 \pm 0.5$

$6.9 \pm 0.1$

2A: Water or hypotonic saline 7

$5.4 \pm 0.1$

$8.7 \pm 0.5$

$144.3 \pm 0.3^{\mathrm{a}}$

$7.0 \pm 0.1$

2A: Iso- or hypertonic saline 10

$6.4 \pm 0.3^{b}$

$9.2 \pm 0.4$

$146.6 \pm 0.4^{\mathrm{a}, \mathrm{b}}$

$7.0 \pm 0.1$

2B: Water

$8 \quad 6.9 \pm 0.5$

$10.7 \pm 0.8$

$140.5 \pm 0.4^{\mathrm{a}}$

$6.4 \pm 0.1^{\mathrm{a}}$

2B: Iso- or hypertonic saline 13

$6.0 \pm 0.4$

$7.9 \pm 0.6^{\mathrm{c}}$

$146.2 \pm 0.6^{\mathrm{d}}$

$6.3 \pm 0.1^{\mathrm{a}}$

Values are $\mathrm{M} \pm \mathrm{SE}, n=$ number of rats. Shown are the times dehydrated rats spent drinking an initial bout, the amounts consumed, and the plasma $\mathrm{Na}^{+}$and protein concentrations when the rats were sacrificed. In experiment 2A, rats were deprived of drinking water for $16 \mathrm{hr}$ before allowed access to nothing $(n=10)$, water $(n=2), 0.05 \mathrm{M} \mathrm{NaCl}(n=2), 0.10 \mathrm{M} \mathrm{NaCl}(n=$ 3), $0.15 \mathrm{M} \mathrm{NaCl}(n=2)$, or $0.20 \mathrm{M} \mathrm{NaCl}(n=8)$. These rats drank continuously for at least 5 min and were sacrificed once they stopped drinking. In experiment 2B, additional dehydrated rats were given access to water $(n=8), 0.15 \mathrm{M} \mathrm{NaCl}(n=6)$, or $0.20 \mathrm{M} \mathrm{NaCl}(n=7)$, and drank for 5-10 min before stopping, whereupon the drinking tube was removed; those rats were 
sacrificed at 15-60 min of the test period.

${ }^{\mathrm{a}} \mathrm{P}<0.01$ in comparison to rats not allowed to drink

${ }^{\mathrm{b}} \mathrm{P}<0.01$ in comparison to rats given water or dilute saline in experiment $2 \mathrm{~A}$

${ }^{\mathrm{c}} \mathrm{P}<0.02$ in comparison to rats given water in experiment $2 \mathrm{~B}$

${ }^{\mathrm{d}} \mathrm{P}<0.001$ in comparison to rats given water in experiment $2 \mathrm{~B}$ 


\section{APPENDIX B}

\section{FIGURES}



Figure 1 Average Fluid Intake for First Hour

Cumulative mean intakes of water, $0.05 \mathrm{M}, 0.10 \mathrm{M}, 0.15 \mathrm{M}$, or $0.20 \mathrm{M} \mathrm{NaCl}$ solution by dehydrated rats as a function of time ( $\mathrm{n}=\mathbf{8}$ in each group). Not shown are the SEs, which ranged from 0.4 to 1.3. Intakes of each fluid were comparable during the first $20 \mathrm{~min}$ of the test period, but thereafter they increased in proportion to the concentration of the ingested fluid (which was increasingly less hydrating). Note the nonlinear scale in the $x$-axis. 


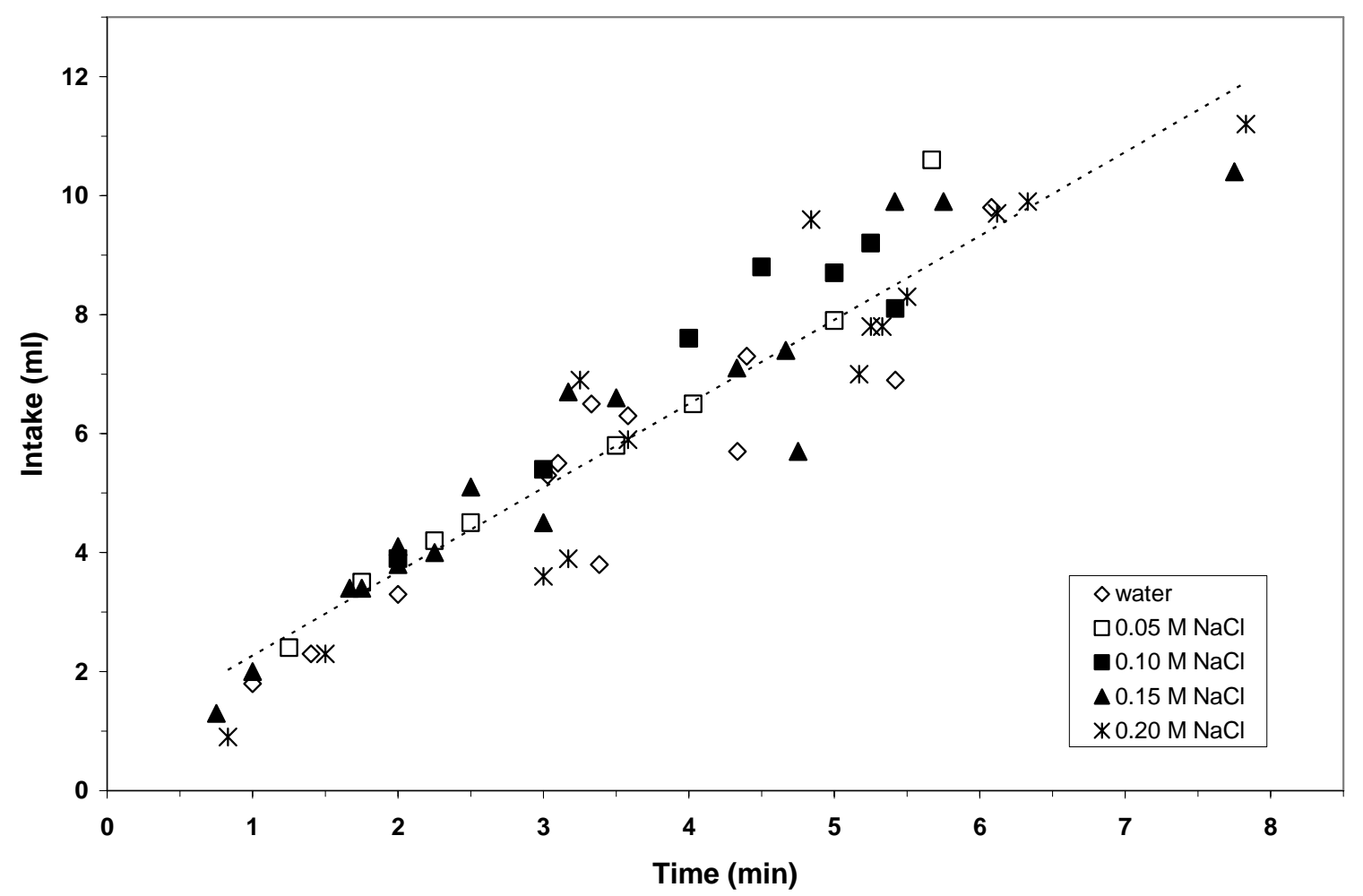

Figure 2 Rate of Intake Across Concentrations

Intake of water, $0.05 \mathrm{M}, 0.10 \mathrm{M}, 0.15 \mathrm{M}$, or $0.20 \mathrm{M} \mathrm{NaCl}$ solution by dehydrated rats, plotted as a function of time spent drinking. Each symbol represents the intake of a single animal. Intakes were highly correlated with time spent drinking regardless of which fluid was consumed $(r=0.94, P<0.001)$. Shown is the regression line for all 58 data points $(y=1.41 x+0.86)$. According to this line, mean drinking rates slowed during this test period from $2.3 \mathrm{ml} / \mathrm{min}$ by rats sacrificed after $1 \mathrm{~min}$ of drinking to $1.5 \mathrm{ml} / \mathrm{min}$ by rats sacrificed after $8 \mathrm{~min}$ of drinking. This decrease reflects the increased incidence of short pauses while rats drank. 

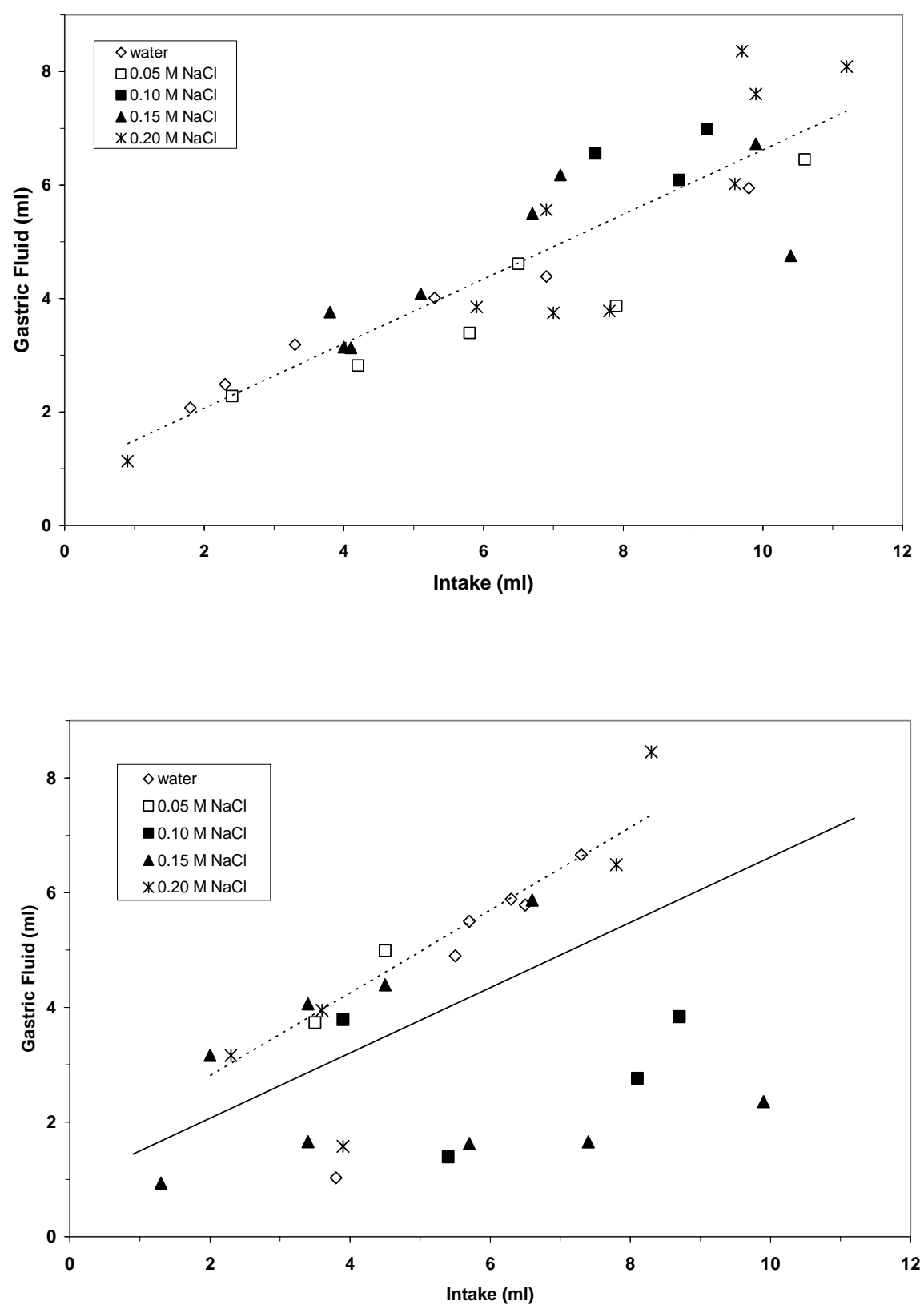

Figure 3A and 3B Gastric Fluid as a Function of Intake

Water in gastric chyme plotted as a function of fluid intake by dehydrated rats. Rats drank either water, 0.05 M, 0.10 M, 0.15 M, or 0.20 M NaCl solution. (A) The dashed line represents the regression line (B) The dashed line represents the regression line for the 10 rats whose gastric solids were $>0.60 \mathrm{~g}(y=0.72 x+$ 1.36). The gastric fluid in these animals was smaller than but proportional to ingested volume $(r=0.96, P$ $<\mathbf{0 . 0 0 1}$ ). Also shown are the consistently smaller gastric fluid volumes in the 10 rats whose gastric solids were $<0.10 \mathrm{~g}$, which indicates that a greater portion of the ingested fluid was emptied. The solid line represents the regression line shown in Fig. 3A and is presented for purposes of comparison 


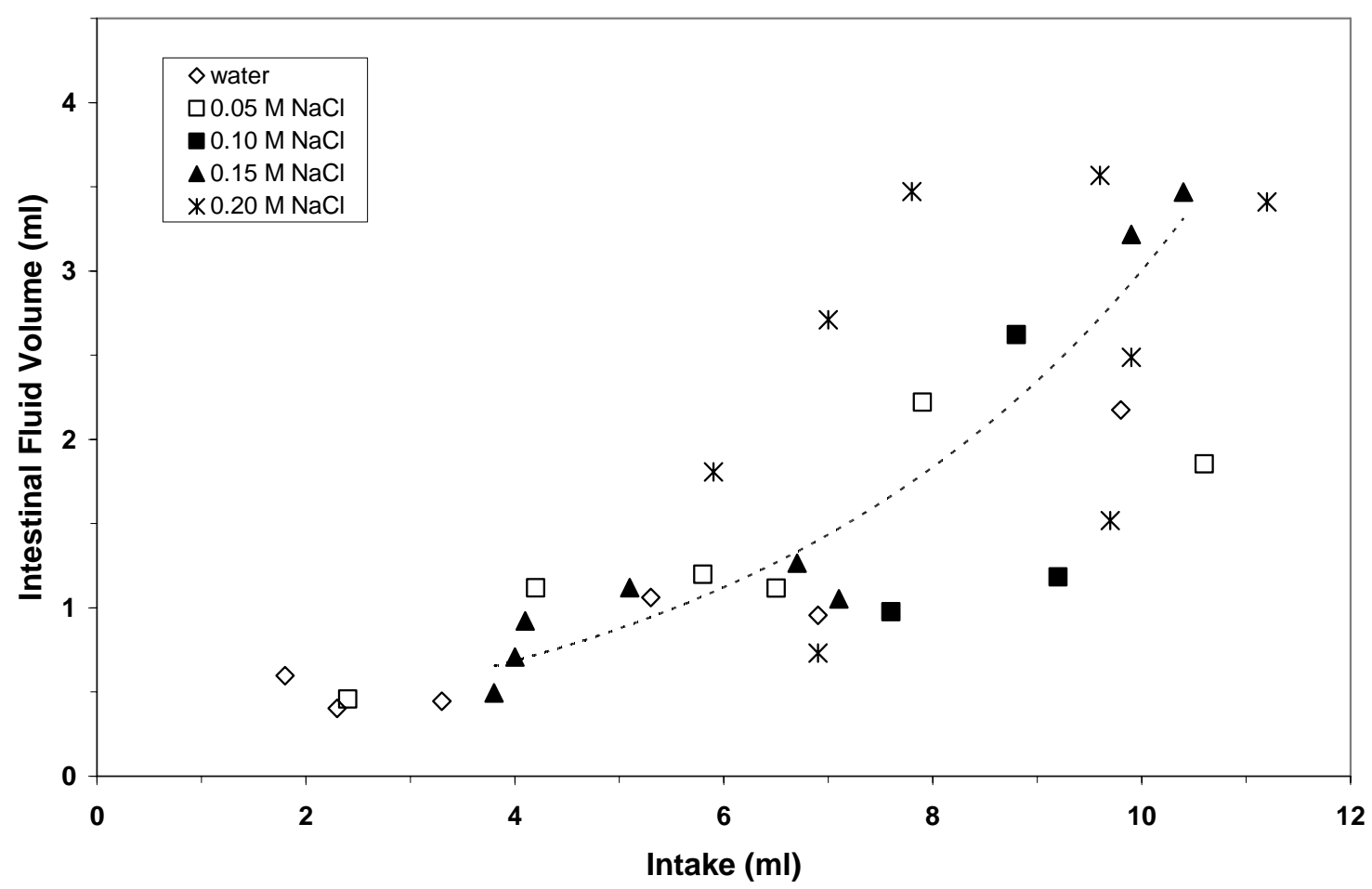

Figure 4 Intestinal Volume

The volume of water in the dye-colored segment of the small intestine, plotted as a function of fluid intake. Symbols represent the same rats whose gastric solids were 0.10-0.60 $\mathrm{g}$, as in the previous figures. Shown is the regression line for all data points $\left(y=0.2561 \mathrm{e}^{0.2461 x}\right)$. The intestinal volume was very small at first but increased exponentially in proportion to fluid intake $(r=0.95, P<0.001)$. 




Figure 5 GI fill

The sum of the measured fluid in the stomach and small intestine of individual rats, plotted as a function of their intake. Symbols represent the same animals as in the previous figures. Shown are two regression lines. One is for rats that drank either water, $0.05 \mathrm{M}, 0.10 \mathrm{M}$, or $0.15 \mathrm{M} \mathrm{NaCl}$ solution (short dashes; $y=0.77 x+0.15$ ), while the other, steeper regression line was for rats drinking $0.20 \mathrm{M} \mathrm{NaCl}$ (long dashes; $y=1.05 x-1.27$ ). In each group, gastrointestinal fill (“GI Fill”) was highly correlated with fluid intake despite the variability in how much the animals consumed $(r=0.96, r=0.99$, respectively; both $P$ s $<\mathbf{0 . 0 0 1 )}$. 


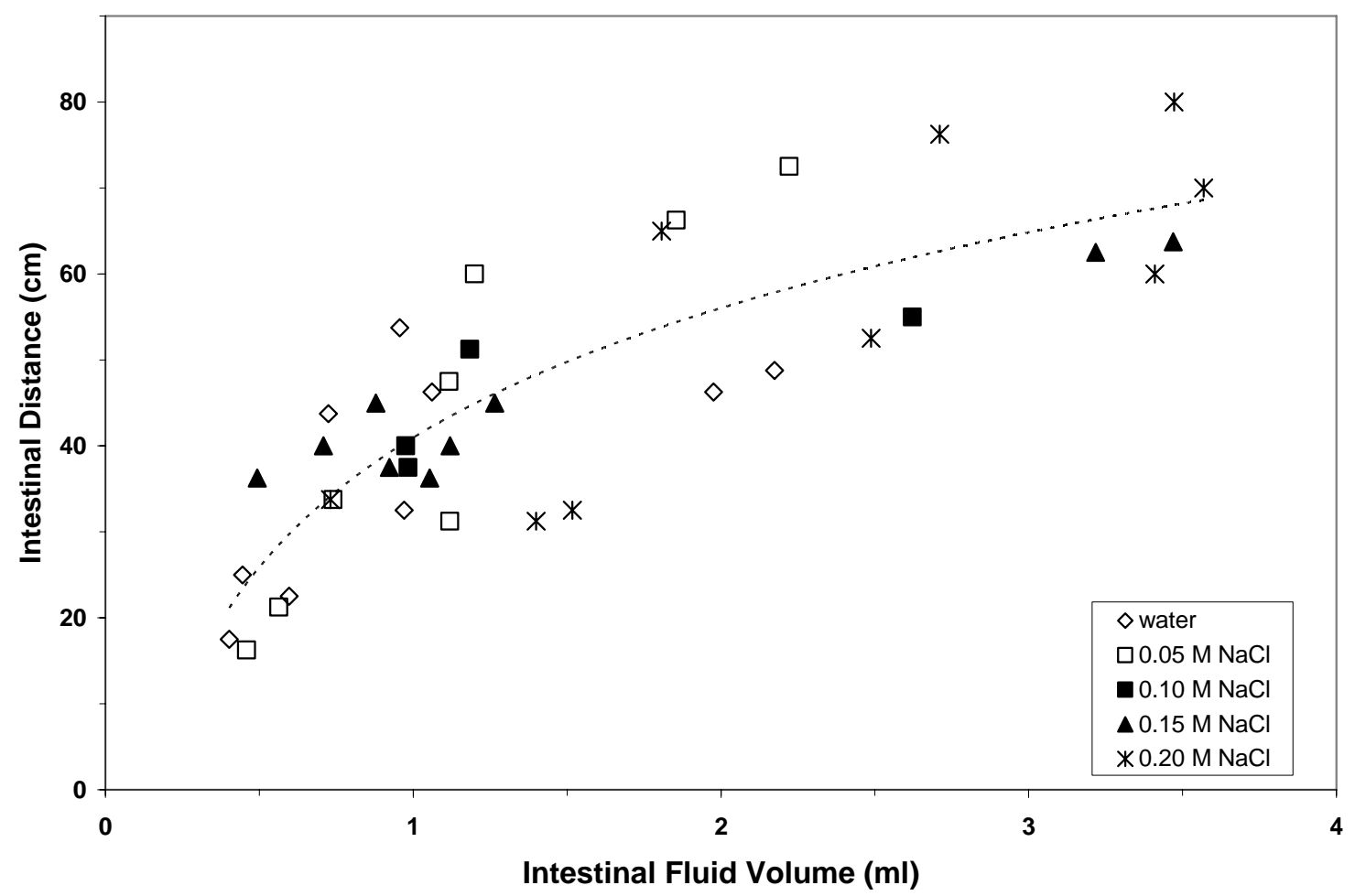

Figure 6 Intestinal Distance Traversed by Dye

Intestinal distance traversed (past the pylorus) by green dye in the ingested fluid, plotted as a function of the volume of ingested fluid in the intestinal lumen. Symbols represent the same animals as in the previous figures. Shown is the logarithmic regression line for all the data points $(y=21.75 \ln (x)+40.95 ; r=$ $0.84, P<0.001)$. The intestinal distance was notably great at first but increased progressively slowly as the volume increased. Note that ingested fluid was not found in the cecum in any rat. 


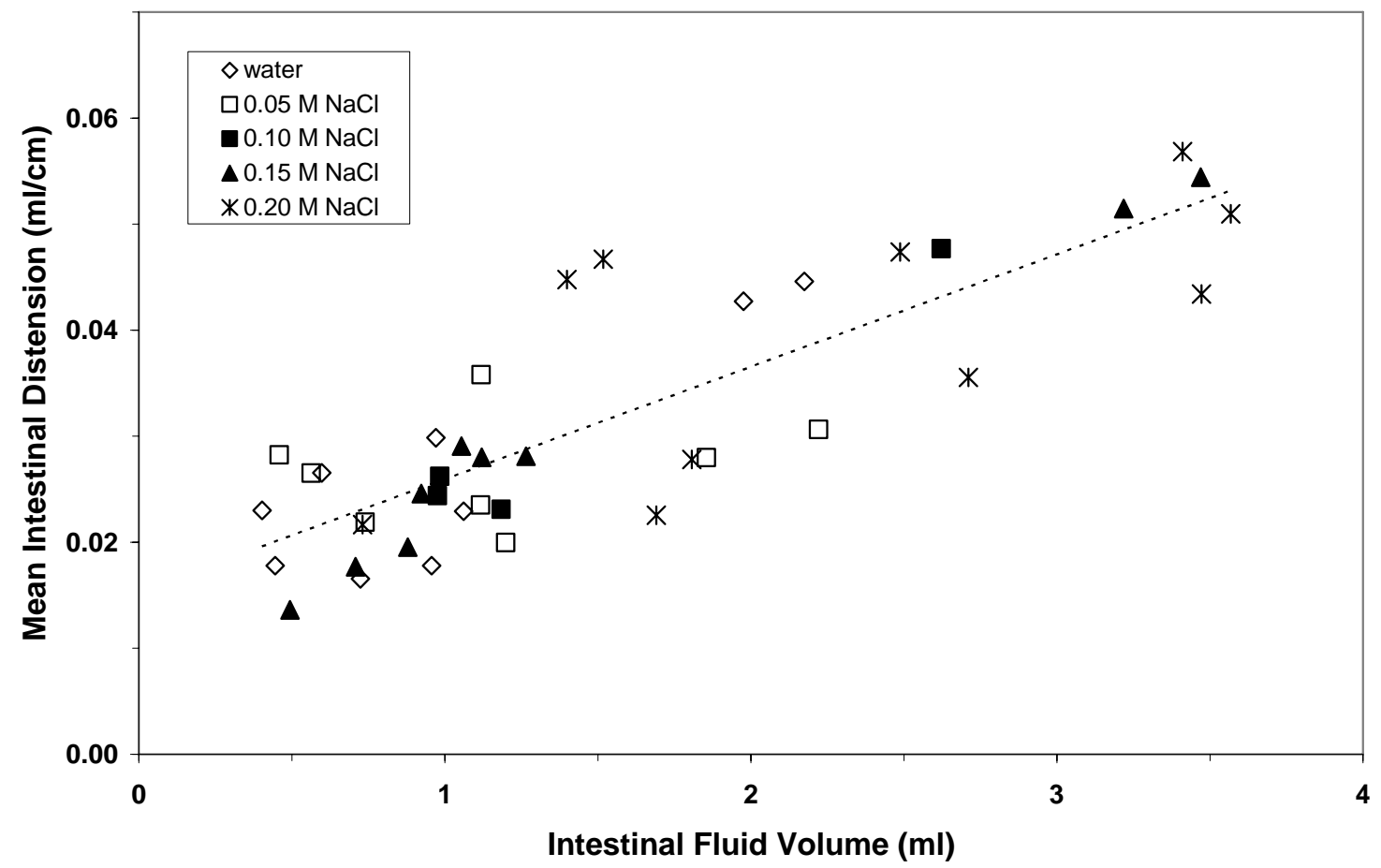

Figure 7 Intestinal Distention

Calculated mean distension of the dye-colored segment of small intestine, plotted as a function of luminal fluid volume in that segment. Symbols represent the same animals as in the previous figures. Shown is the linear regression line for all the data points $(y=0.010 x+0.015 ; r=0.85, P<0.001)$. The mean distension increased progressively as fluid entered the small intestine. Note that the dye-colored fluid actually was not distributed uniformly within the intestinal segment; instead, intervals containing little or no fluid punctuated the segment. 




Figure 8 GI fill During First Hour

Volume of fluid in the stomach and small intestine (“GI Fill”), expressed as a percent of the volume consumed in an initial bout and plotted as a function of time. Dehydrated rats drank water, $0.15 \mathrm{M} \mathrm{NaCl}$, or 0.20 M NaCl solution. Symbols represent individual animals. GI fill decreased rapidly when rats ingested water or isotonic saline, whereas it was slower when the hypertonic solution was consumed. 


\section{REFERENCES}

Adolph EF. Thirst and its inhibition in the stomach. Am J Physiol 161: 374-386, 1950.

Appelgren BH, Thrasher TN, Keil LC, and Ramsay DJ. Mechanism of drinking-induced inhibition of vasopressin secretion in dehydrated dogs. Am J Physiol Regulatory Integrative Comp Physiol 261: 1226-1233, 1991.

Arnauld E and DuPont J. Vasopressin release and firing of supraoptic neuro-secretory neurons during drinking in the dehydrated monkey. Pfluegers Arch 394: 195-201, 1982.

Baertschi AJ and Pence RA. Gut-brain signaling of water absorption inhibits vasopressin in rats. Am J Physiol Regul Integr Comp Physiol 268: R236-R247, 1995.

Baertschi AJ and Vallet PG. Osmosensitivity of the hepatic portal vein area and vasopressin release in rats. J Physiol 315: 217-230, 1981.

Bárdos G. Fluid intake and behavioral changes in rats associated with the distension of the small and large intestine. Behav Neurosci 111: 834-844, 1997.

Blair-West JR, Gibson AP, Woods RL, and Brook AH. Acute reduction of plasma vasopressin levels by rehydration in sheep. Am J Physiol Regulatory Integrative Comp Physiol 248: R68R71, 1985.

Blass EM and Hall WG. Drinking termination: Interactions among hydrational, orogastric, and behavioral controls in rats. Psychol Rev 83: 356-374, 1976. 
Choi-Kwon S, McCarty R, and Baertschi AJ. Splanchnic control of vasopressin secretion in conscious rats. Am J Physiol Endocrinol Metab 259: E19-E26, 1990.

Curtis, KS and Stricker, EM. Enhanced fluid intake by rats after capsaicin treatment. Am $J$ Physiol Regul Integr Comp Physiol 272: R704-R709, 1997.

Curtis KS, Verbalis JG, and Stricker EM. Area postrema lesions in rats appear to disrupt rapid feedback inhibition of fluid intake. Brain Res 726: 31-38, 1996.

Davis JD and Sayler JL. Effects of confining ingested fluid to the stomach on water and saline intake in the rat. Physiol Behav 61: 127-130, 1997.

Davis JD, Smith GP, and McCann DP. The control of water and sodium chloride intake by postingestional and orosensory stimulation in water-deprived rats. Physiol Behav 75: 7-14, 2002.

Deen PM, Verdijk MA, Knoers NV, Wieringa B, Monnens LA, van Os CH, and van Oost BA. Requirement of human renal water channel aquaporin-2 for vasopressin-dependant concentration of urine. Science 264: 92-95, 1994.

Dunn FL, Brennan TJ, Nelson AE, and Robertson GL. The role of blood osmolality and volume in regulating vasopressin secretion in the rat. J Clin Invest 52: 3212-3219, 1973.

Elkinton JR. Prerequisite of freedom: A hypertonic urine. Ann Int Med 54: 827-831, 1961.

Fitzsimons JT. The effects of slow infusions of hypertonic solutions on drinking and drinking thresholds in rats. $J$ Physol (Lond) 167: 344-354, 1963.

Fox EA, Phillips RJ, Baronowsky EA, Byerly MS, Jones S, and Powley TL. Neurotrophin-4 deficient mice have a loss of vagal intraganglionic mechanoreceptors from the small intestine and a disruption of short-term satiety. J Neurosci 21: 8602-8615, 2001. 
Gardiner TW, Verbalis JG, and Stricker EM. Impaired secretion of vasopressin and oxytocin in rats after lesions of the nucleus medianus. Am J Physiol Regulatory Integrative Comp Physiol 249: R681-R688, 1985.

Geelen G, Keil LC, Kravik SE, Wade CE, Thrasher TN, Barnes PR, Pyka G, Nesvig C, and Greenleaf JE. Inhibition of plasma vasopressin after drinking in dehydrated humans. Am J Physiol Regulatory Integrative Comp Physiol 247: R968-R971, 1984.

Hall WG and Blass EM. Orogastric, hydrational and behavioral controls of drinking following water deprivation in rats. J Comp Physiol Psychol 89: 954-969, 1975.

Hall WG and Blass EM. Orogastric determinants of drinking in rats: Interaction between absorptive and peripheral controls. J Comp Physiol Psychol 91: 365-373, 1977.

Hatton GI and Bennett CT. Satiation of thirst and termination of drinking: Roles of plasma osmolality and absorption. Physiol Behav 5: 479-487, 1970.

Hoffmann ML, Denbleyker M, Smith JC, and Stricker EM. Inhibition of thirst when dehydrated rats drink water of saline. Am J Physiol Regul Integr Comp Physiol, in press, 2006, available online.

Hoffmann ML and Stricker EM. Presystemic stimulation of vasopressin secretion in rats while eating high- $\mathrm{NaCl}$ diet. Poster presented at the annual meeting for the Society of Neuroscience, Washington D.C., October 2005.

Huang W, Sved AF, and Stricker EM. Water ingestion provides an early signal inhibiting osmotically stimulated vasopressin secretion in rats. Am J Physiol Regul Integr Comp Physiol 279: R756-R760, 2000. 
Kraly FS, Kim YM, Dunham LM, and Tribuzio RA. Drinking after intragastric $\mathrm{NaCl}$ without increase in systemic plasma osmolality in rats. Am J Physiol Regul Integr Comp Physiol 269: R1085-R1092, 1985.

Manesh R, Hoffmann ML, and Stricker EM. Water ingestion by rats fed high-salt diet may be mediated, in part, by visceral osmoreceptors. Am J Physiol Regul Integr Comp Physiol, in press, 2006.

Mangiapane ML, Thrasher TN, Keil LC, Simpson JB, and Ganong WF. Deficits in drinking and vasopressin secretion after lesions of the nucleus medianus. Neuroendocrinology 37: 73-77, 1983.

Mathis C, Moran TH, and Schwartz GJ. Load-sensitive rat gastric vagal afferents encode volume but not gastric nutrients. Am J Physiol Regulatory Integrative Comp Physiol 274: R280R286, 1998.

Morita H, Yamashita Y, Nishida Y, Tokuda M, Hatase O, and Hosomi H. Fos induction in rat brain neurons after stimulation of the hepatoportal Na-sensitive mechanism. Am J Physiol Regulatory Integrative Comp Physiol 272: R913-R923, 1997.

Nielsen S, Chou CL, Marples D, Christensen EI, Kishore BK, and Knepper MA. Vasopressin increases water permeability of kidney collecting duct by inducing translocation of aquaporinCD water channels to the plasma membrane. Proc Natl Acad Sci U.S.A. 94:1013-1017, 1995.

Norgren R and Smith GP. Central distribution of the subdiaphragmatic vagal branches in the rat. J Comp Neurol 273: 207-223, 1988.

Oldfield BJ, Badoer E, Hards DK, and McKinley MJ. Fos production in retrogradely labeled neurons of the lamina terminalis following intravenous infusion of either hypertonic saline or angiotensin II. Neuroscience 6: 255-262, 1994. 
Ramsay DJ, Rolls BJ, and Wood RJ. Body fluid changes which influence drinking in the waterdeprived rat. J Physiol (London) 266: 453-469, 1977.

Schwartz GJ, Salorio CF, Skoglund C, and Moran TH. Gut vagal afferent lesions increase meal size but do not block gastric preload-induced feeding suppression. Am J Physiol Regulatory Integrative Comp Physiol 276: R1623-R1629, 1999.

Seckl JR, Williams TD, and Lightman SL. Oral hypertonic saline causes transient fall of vasopressin in humans. Am J Physiol Regulatory Integrative Comp Physiol 251: R214-R217, 1986.

Smith CA and Stricker EM. Early inhibition of fluid consumption in hypovolemic rats. Poster presented at annual meeting of the Society for the Study of Ingestive Behavior, Pittsburgh, PA, July 2005.

Smith CA and Stricker EM. Intestinal denervation eliminates the rapid inhibitory signal associated with distention of the stomach and small intestine when dehydrated rats drink water. Poster to be presented at the international meeting of Society for the Study of Ingestive Behavior, Naples FL, July 2006.

Smith JC. Microstructure of the rat's intake of food, sucrose and saccharin. Neurosci Biobeh Rev 24: 199-212, 2000.

Stricker EM. Some physiological and motivational properties of the hypovolemic stimulus for thirst. Physiol Behav 3: 379-385, 1968.

Stricker EM. Osmoregulation and volume regulation in rats: Inhibition of hypovolemic thirst by water. Am J Physiol 217: 98-105, 1969.

Stricker EM. Influence of saliva on feeding behavior in the rat. J Comp Physiol Psychol 70: 103112, 1970. 
Stricker EM, Callahan JB, Huang W, and Sved AF. Early osmoregulatory stimulation of neurohypophyseal hormone secretion and thirst after $\mathrm{NaCl}$ loads. Am J Physiol Regul Integr Comp Physiol 282: R1710-R1717, 2002.

Stricker EM, Craver CF, Curtis KS, Peacock-Kinzig KA, Sved AF, and Smith JC. Osmoregulation in water-deprived rats drinking hypertonic saline: effect of area postrema lesions. Am J Physiol Regulatory Integrative Comp Physiol 280: R831-R842, 2001.

Stricker EM and Hoffmann ML. Inhibition of vasopressin secretion when dehydrated rats drink water. Am J Physiol Regul Integr Comp Physiol 289: R1238-R1243, 2005.

Stricker EM, Hoffmann ML, Riccardi CJ, and Smith JC. Increased water intake by rats maintained on high salt diet: analysis of ingestive behavior. Physiol Behavior 70: 621-631, 2003.

Stricker EM and Jalowiec JE. Restoration of intravascular fluid volume following acute hypovolemia in rats. Am J Physiol 218: 191-196, 1970.

Stricker EM and Verbalis JG. Fluid intake and homeostasis. In: Squire LR, Bloom FE, McConnell SK, Roberts JL, Spitzer NC, and Zigmond MJ, eds. Fundamental Neuroscience, $2^{\text {nd }}$ edition. San Diego: Academic, 2002, pp. 1011-1029.

Stricker EM and Verbalis JG. Interaction of osmotic and volume stimuli in regulation of neurohypophyseal secretion in rats. Am J Physiol Regulatory Integrative Comp Physiol. 250: R267-R275, 1986.

Thrasher TN, Keil LC, and Ramsay DJ. Lesions of the organum vasculosum of the lamina terminalis (OVLT) attenuate osmotically-induced drinking and vasopressin secretion in the dog. Endocrinology 110:1837-1839, 1982.

Thrasher TN, Nistal-Herrera JF, Keil LC, and Ramsay DJ. Satiety and inhibition of vasopressin secretion after drinking in dehydrated dogs. Am J Physiol Endocr Metab 240: E394-E401, 1981. 
Vallet P and Baertschi AJ. Sodium-chloride sensitive receptors located in the hepatic portal vein of the rat. Neurosci Letters 17: 283-288, 1980.

Vaughan JE, Hoffmann ML, Smith JC, and Stricker EM. Inhibition of intake when thirsty rats drink water: A comparison of two models of thirst. Poster presented at international meeting of Society for the Study of Ingestive Behavior, July 2005, Pittsburgh, PA.

Verbalis JG, Mangione MP, and Stricker EM. Oxytocin produces natriuresis in rats at physiological plasma concentrations. Endocrinology 128: 1317-1322, 1991.

Waldbillig RJ and Lynch WC. Oroesophageal factors in the patterning of drinking. Physiol Behav 22: 205-209, 1979.

Wang FB and Powley TL. Topographic inventories of vagal afferents in gastrointestinal muscle. J Comp Neurol 421: 302-324, 2000. 